\title{
An Empirical Formulation for Predicting Welding-Induced Biaxial Compressive Residual Stresses on Steel Stiffened Plate Structures and Its Application to Thermal Plate Buckling Prevention
}

\author{
Myung Su Yi ${ }^{\mathrm{a}, \mathrm{b}}$, Chung Min Hyun ${ }^{\mathrm{b}}$ and Jeom Kee Paik ${ }^{\mathrm{a}, \mathrm{c}, \mathrm{d}^{*}}$ \\ ${ }^{a}$ Department of Naval Architecture and Ocean Engineering, Pusan National University, Busan 46241, Korea \\ ${ }^{b}$ Ship \& Offshore Research Institute, Samsung Heavy Industries Co., Ltd., Geoje, Gyeongsangnam-do 53261, Korea \\ 'The International Centre for Advanced Safety Studies (The Lloyd's Register Foundation Research Centre of Excellence), Pusan \\ National University, Busan 46241, Korea \\ ${ }^{d}$ Department of Mechanical Engineering, University College London, London WC1E 7JE, UK
}

\begin{abstract}
The aim of this paper is to derive an empirical formulation for predicting welding-induced biaxial compressive residual stresses in welded steel plate panels. A test database for full-scale models of welded steel plate structures is developed. Elastic-plastic finite element method solutions, associated with thermal stresses in welded steel plate panels, are also developed. The proposed formula is derived by a curve fitting of the databases obtained from both full-scale measurements and numerical computations as a function of plate thickness and weld leg length. The paper demonstrates an applied example of the derived formulations to prevent the thermal buckling of thin steel plate panels that occurs during the welding process.
\end{abstract}

Keywords: Welding-induced residual stresses; steel stiffened plate structures; full-scale residual stress measurements; elastic-plastic thermal stress finite element method analysis; thermal plate buckling

\section{Introduction}

Living quarters of ships and offshore structures as shown in Figure 1 are made of thin plate panels with a plate thickness of $6-8 \mathrm{~mm}$. During welding process, thermal buckling causes significant amount of distortions in plate panels as shown in Figure 2 where door frames are seriously twisted and walls deflect significantly. In this case, it is inevitably required to perform fairing works as shown in Figure 3 which are costly and are delaying the building schedule.

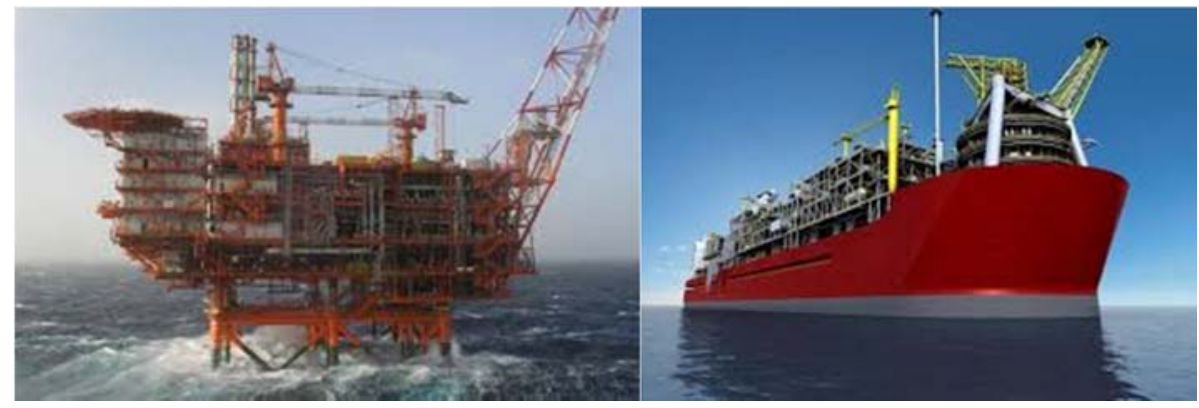

Figure 1. Living quarters of ships and offshore structures made of thin plate panels. 


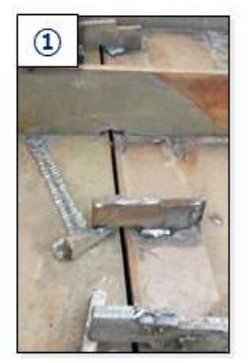

Plate edge misalignment

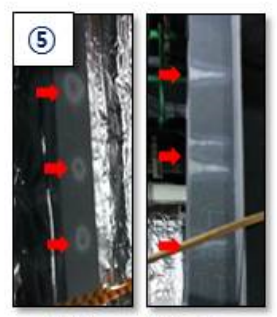

Stiffener distortions

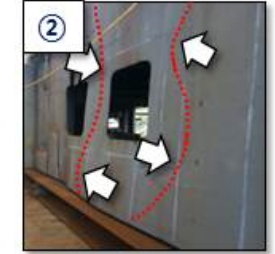

Unexpected deformation

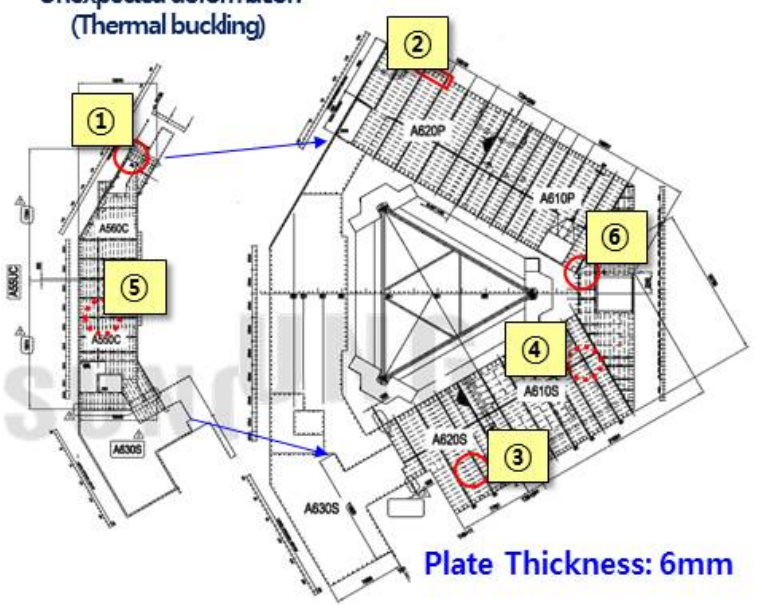

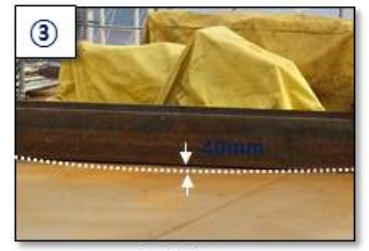

Deck deflection
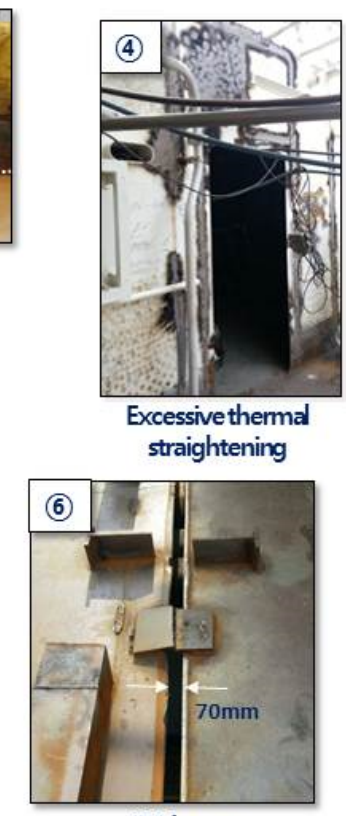

Wide gap

Figure 2. Welding-induced deformations during welding process (Living quarter of offshore structure made by Samsung Heavy industry co., Ltd.).
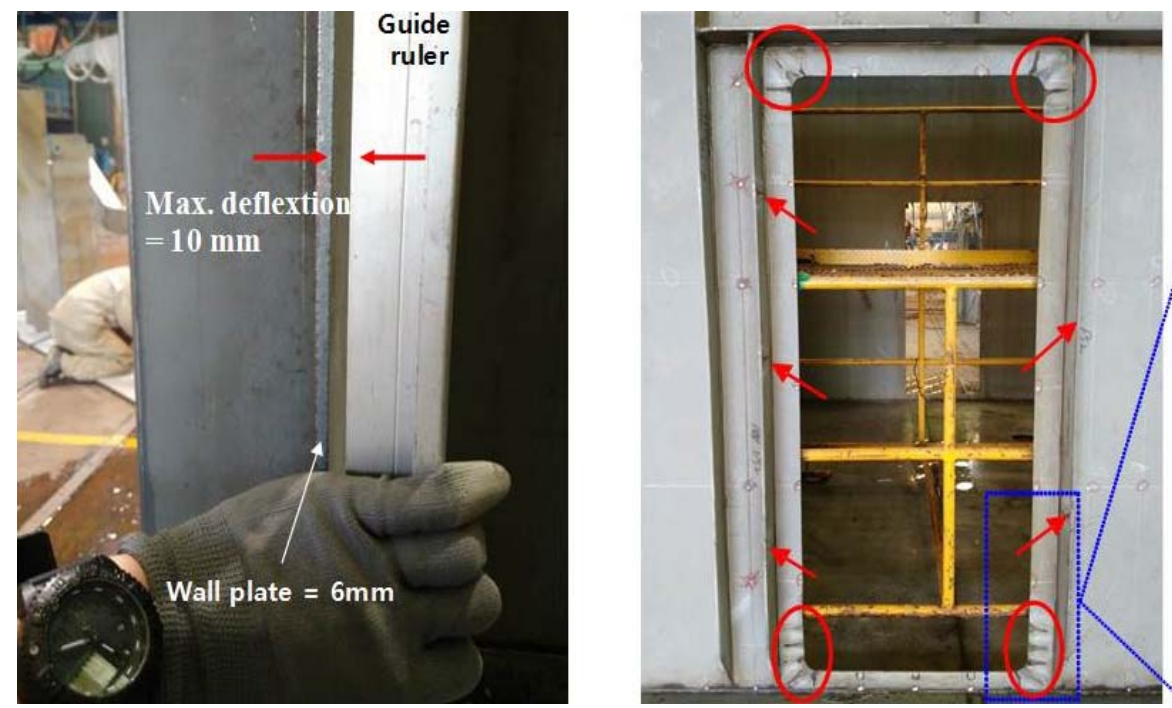

Fairing

Figure 3. Costly fairing works to distorted plate panels

Thermal buckling occurs in plate panels during welding process if welding-induced biaxial compressive residual stresses exceed the plate bucking strength. To prevent the thermal plate buckling, two options may be relevant:

- Option 1: Reduce the welding-induced biaxial compressive residual stresses

- Option 2: Increase the plate buckling strength

Option 1 can be achieved by mitigating the welding conditions, e.g., reducing the weld leg length with minimum heat sources. However, this option requires much advanced workmanship of welding and it is not straightforward to apply in shipyards. Option 2 can be achieved by increasing plate 
thickness, but this approach is not acceptable as it essentially increases the structural weight. Rather, the plate buckling strength can be effectively increased by increasing the torsional rigidities of support members even without the increase of plate thickness (Paik 2018). The final goal of the present study is to develop an innovative technology to prevent thermal plate buckling during welding process. For this purpose, it is required to predict the welding-induced biaxial compressive residual stresses which are described in the present paper.

Plated structures such as ships and offshore structures are constructed by welding to attach support members (e.g., longitudinal stiffeners and transverse frames) to the plating as shown in Figure 4. In this process, initial imperfections develop in the form of deformations and residual stresses. Figure 5 shows the types of welding-induced initial deformations or distortions in plated structures. As support members are attached in both longitudinal and transverse directions of plate panels, the weldinginduced residual stresses can develop in the two directions, as shown in Figure 6.

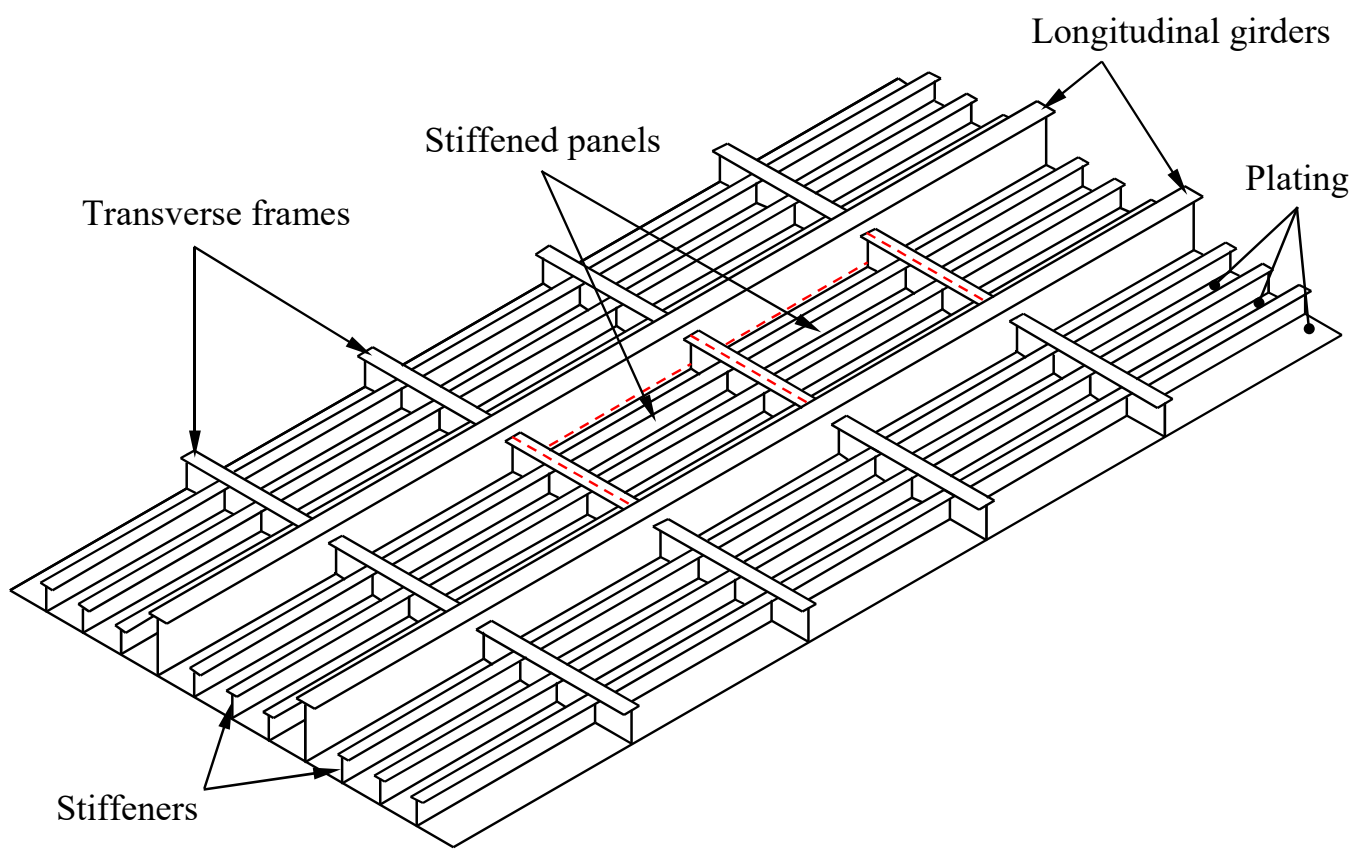

Figure 4. A stiffened plate structure (Paik 2018).

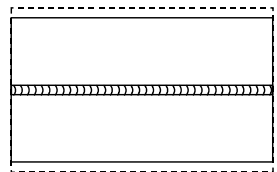

Transverse Shrinkage

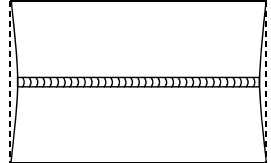

Longitudinal Shrinkage

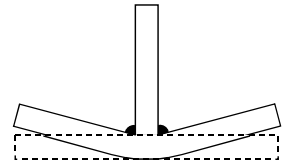

Angular Distortion

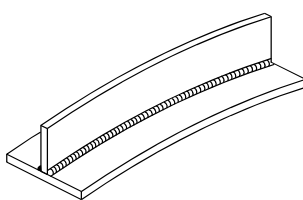

Longitudinal Bending Distortion

Figure 5. Types of welding-induced distortion in plated structures (Paik 2018). 

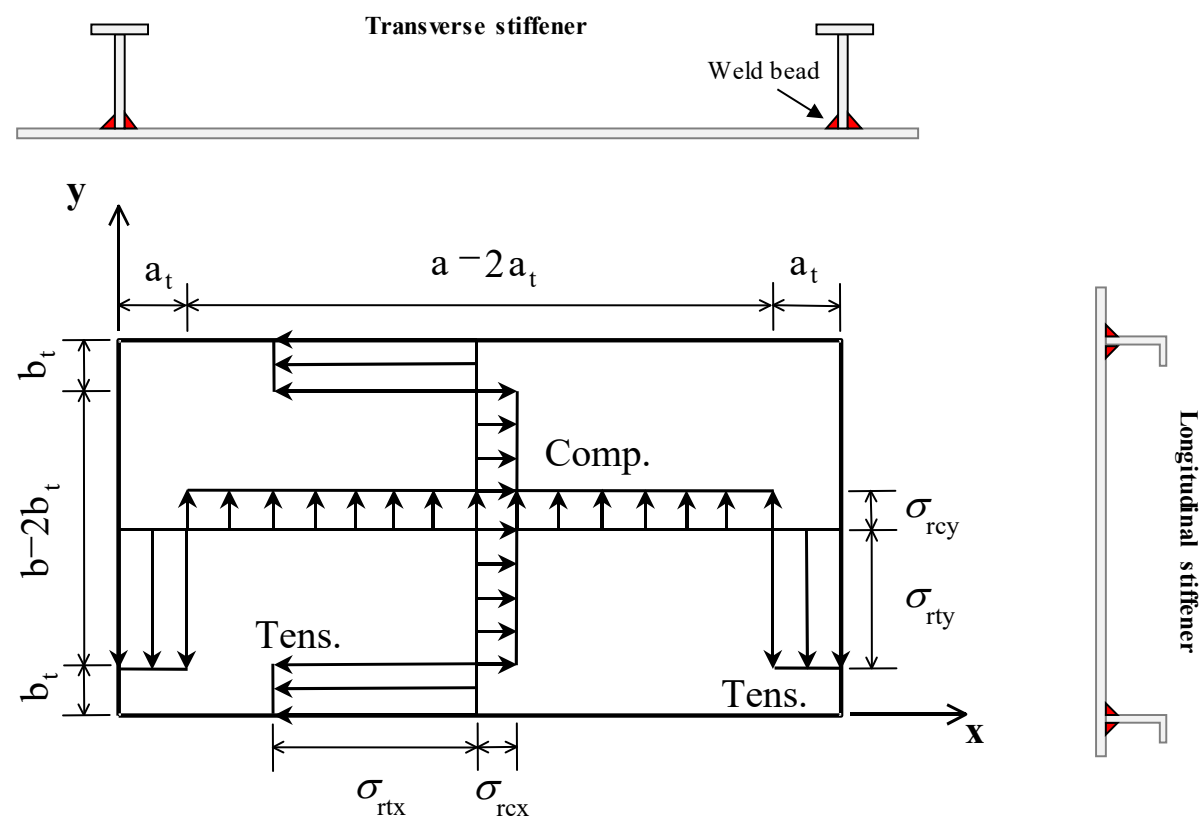

Figure 6. Idealized distribution of welding-induced residual stresses in both longitudinal and transverse directions of stiffened plate structures (Paik 2018).

In addition to unwanted fairing works, such welding-induced initial imperfections also affect buckling and the ultimate strength of these structures (Paik 2018). It is therefore of paramount importance to predict the magnitude and pattern of welding-induced initial imperfections and their effects on buckling and ultimate strength. This paper focuses on the prediction of welding-induced residual stresses on steel stiffened plate structures.

A number of related studies are available in the literature in association with the direct measurement of welding-induced initial imperfections in steel or aluminium stiffened plate structures. For example, Masubuchi (1980), Smith et al. (1988), Ueda (1999), Paik et al. (2006), Paik (2007c, 2008), Paik et al. (2008, 2012), Vhanmane et al. (2008), Luís et al. (2009), Bruno et al. (2011), Khedmati et al. (2012), and Teresa et al. (2013) provided measurement databases for the initial distortions of aluminum-plated structures; Masubuchi (1980), Smith et al. (1988), Cheng et al. (1996), Ueda (1999), and Kenno et al. (2010, 2017) produced measurement databases for the residual stress on steel-plated structures; and Paik et al. (2006), Paik (2008), and Paik et al. $(2008,2012)$ provided measurement database for residual stresses and the softening of aluminum-plated structures. Eggert et al. (2012) and Lillemäe et al. (2017) studied the effects of welding-induced residual stresses on the fatigue strength of steel-plated structures. Khan et al. (2011), Gannon et al. (2012a, 2012b, 2015), Farajkhah et al. (2016), and Chen et al. (2018) also contributed to solving the problem. A survey of the literature suggests that there is a lack of direct measurement databases of welding-induced residual stresses on full-scale steel stiffened plate structure models, even though there is a demand for such full-scale measurements to secure the reliability of the prediction methods.

In this paper, measurement databases for welding-induced residual stresses on full-scale models of steel stiffened plate structures are developed and then associated with other research (Yi et al. 2018b). An extensive study of elastic-plastic finite element method computations was also undertaken while varying the plate thickness and the weld leg length on the same models of steel stiffened plate 
structures, which were considered for direct measurements of welding-induced residual stresses. Based on both full-scale measurements and numerical computations, an empirical formulation was derived by curve fitting to predict welding-induced residual stresses on steel stiffened panels. The derived formulations of welding-induced residual stresses were applied to design thin steel plate panels, thereby preventing the thermal buckling that may occur in the welding process.

\section{Investigated structures}

Figure 7 shows the two-bay model of steel stiffened plate structures considered in this study, which are associated with the direct measurements and finite element method analyses detailed in separate papers (Yi et al. 2018a). Longitudinal stiffeners have an angle type and transverse frames have a T-bar type, as shown in Figure 8. Tables 1 and 2 indicate the dimensions and the mechanical properties of the object structures.

In this paper, we did not perform tensile coupon tests to define the material properties. Table 2 presents nominal values of mechanical properties obtained from POSCO steel mill certification.

The support members were attached by fillet welding using flux cored arc welding (FCAW) technique, and the details of welding conditions are provided in Table 3 where one-pass welding was applied.
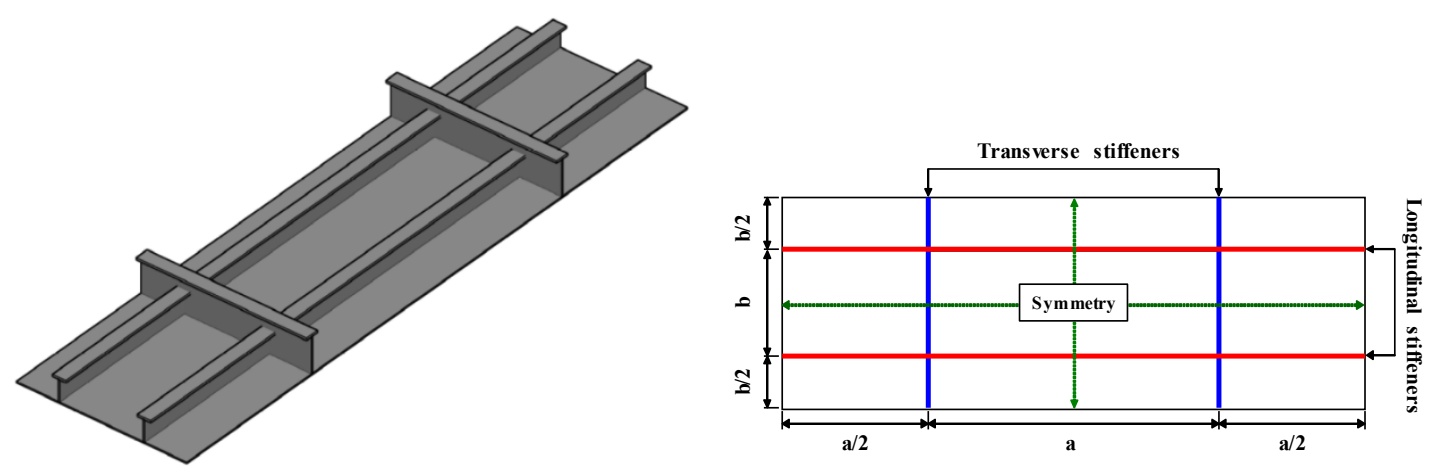

Figure 7. The two-bay model of steel stiffened plate structures considered in this study.

$\mathrm{b}$

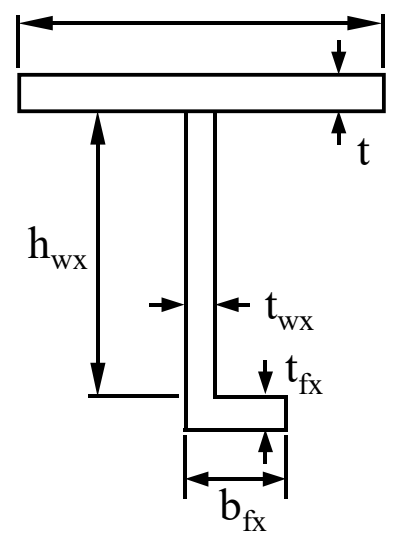

(a) Longitudinal stiffener a

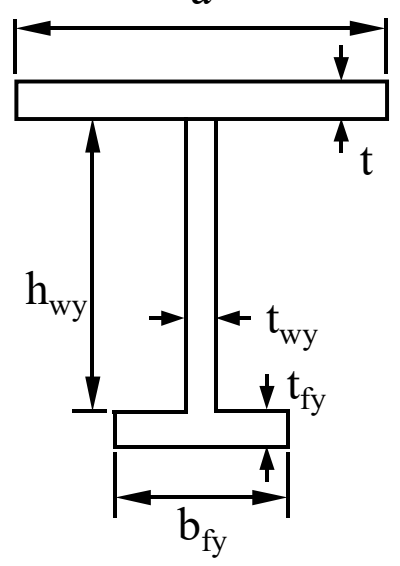

(b) Transverse frame

Figure 8. Types of support members used for the object structures. 
Table 1. Dimensions of the test structures.

\begin{tabular}{|c|c|c|c|c|c|c|c|c|}
\hline$a(\mathrm{~mm})$ & $b(\mathrm{~mm})$ & $t(\mathrm{~mm})$ & $L_{w}(\mathrm{~mm})$ & $\begin{array}{c}\text { Stiffener } \\
\text { Type } \\
\end{array}$ & $\begin{array}{c}h_{w} \\
(\mathrm{~mm}) \\
\end{array}$ & $t_{w}(\mathrm{~mm})$ & $b_{f}(\mathrm{~mm})$ & $\begin{array}{c}t_{f} \\
(\mathrm{~mm}) \\
\end{array}$ \\
\hline \multirow{4}{*}{3,200} & \multirow{4}{*}{800} & 6 & \multirow{4}{*}{6.5} & Longitudinal & \multirow{2}{*}{125} & \multirow{2}{*}{7} & \multirow{2}{*}{75} & \multirow{2}{*}{7} \\
\hline & & 8 & & (Angle type) & & & & \\
\hline & & 10 & & Transverse & \multirow{2}{*}{350} & \multirow{2}{*}{12} & \multirow{2}{*}{100} & \multirow{2}{*}{17} \\
\hline & & 12 & & (T-bar type) & & & & \\
\hline
\end{tabular}

Note: $L_{w}$ is the weld leg length, which is defined in Figure 9.

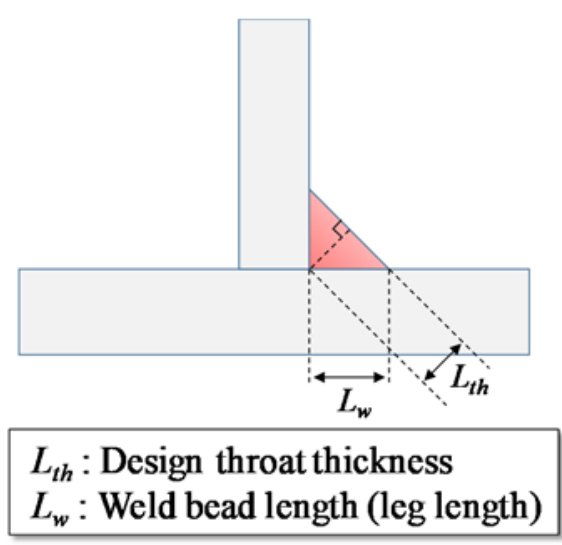

Figure 9. Nomenclature of the weld leg length.

Table 2. Overall characteristics of mechanical properties.

\begin{tabular}{|c|c|c|c|c|c|}
\hline Kind of material & $E(\mathrm{GPa})$ & $\sigma_{Y}(\mathrm{MPa})$ & $\sigma_{u}(\mathrm{MPa})$ & $v$ & $\varepsilon_{f}(\mathrm{~mm} / \mathrm{mm})$ \\
\hline \hline Mild steel (Grade A) & 203 & 309 & 458 & 0.3 & 0.23 \\
\hline
\end{tabular}

Note: $E$ is the elastic modulus, $\sigma_{Y}$ is the yield strength, $\sigma_{u}$ is the ultimate tensile strength, $v$ is the Poisson ratio, and $\varepsilon_{f}$ is the fracture strain (elongation).

Table 3. Welding conditions to attach the support members.

\begin{tabular}{|c|c|c|c|c|c|}
\hline$L_{w}(\mathrm{~mm})$ & Current $(\mathrm{A})$ & Voltage $(\mathrm{V})$ & Speed $(\mathrm{CPM})$ & $\begin{array}{c}\text { Speed } \\
(\mathrm{mm} / \mathrm{s})\end{array}$ & $\begin{array}{c}\text { Heat input } \\
(\mathrm{kJ} / \mathrm{mm})\end{array}$ \\
\hline \hline 6.5 & 320 & 32 & 36 & 6.0 & 1.71 \\
\hline
\end{tabular}

\section{Finite element modeling and direct measurements}

The details of finite element method modeling and the direct measurements of welding-induced residual stresses are presented in separate papers (Yi et al. 2018a, 2018b), but a brief summary is given here.

\subsection{Finite element modeling}

To analyze welding-induced residual stresses on steel stiffened plate structures, the threedimensional thermo-elastic-plastic finite element analysis method is applied using the MSC/MARC program (MSC 2013). Figure 10 shows the extent of the analysis undertaken in this study. In this paper, phase transformation is considered. Also, temperature depended thermal and mechanical properties are 
used in this analysis. These properties were applied using data from previous researchers. In order to reduce the analysis time, $1 / 4$ model applying symmetry condition has been used. A time-dependent transient analysis method is used, after validating the heat source model (Goldak's double ellipsoidal model) using the welding temperature measuring experiment. (Yi et al. 2018a).

Figure 11 shows a typical mesh model applied for the purpose of thermal analysis. The size of finite elements is about $3 \mathrm{~mm} \times 3 \mathrm{~mm} \times \mathrm{t} \mathrm{mm}$ (length $\times$ breadth $\times$ thickness). Figure 11 also presents the welding sequences that are divided into eight stages, which is the same as in the actual welding process. The finite elements used are eight-node three-dimensional brick thermal-mechanical finite elements (also called Solid 7 (full integration type)) elements that address plasticity, hyper-elasticity, stress stiffening, creep, large deflection, and large strain capabilities (MSC 2013). In the finite element analyses, the plate thickness is varied at $6,8,10$, and $12 \mathrm{~mm}$, and the weld leg length is varied at 3.5 , $4.5,6,6.5$, and $8 \mathrm{~mm}$.

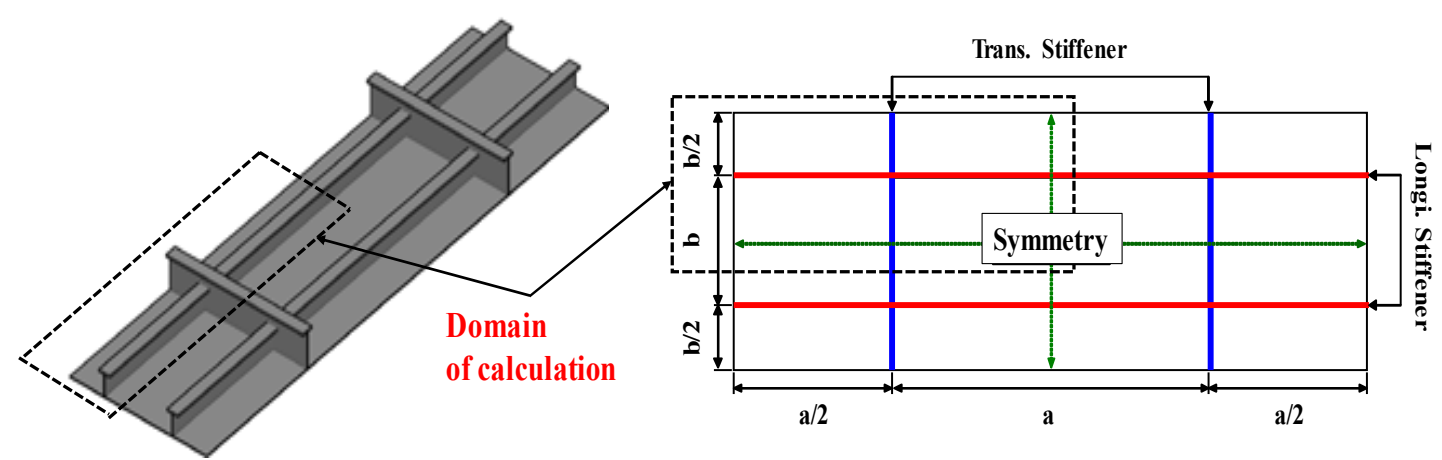

Figure 10. The extent of the finite element analysis.

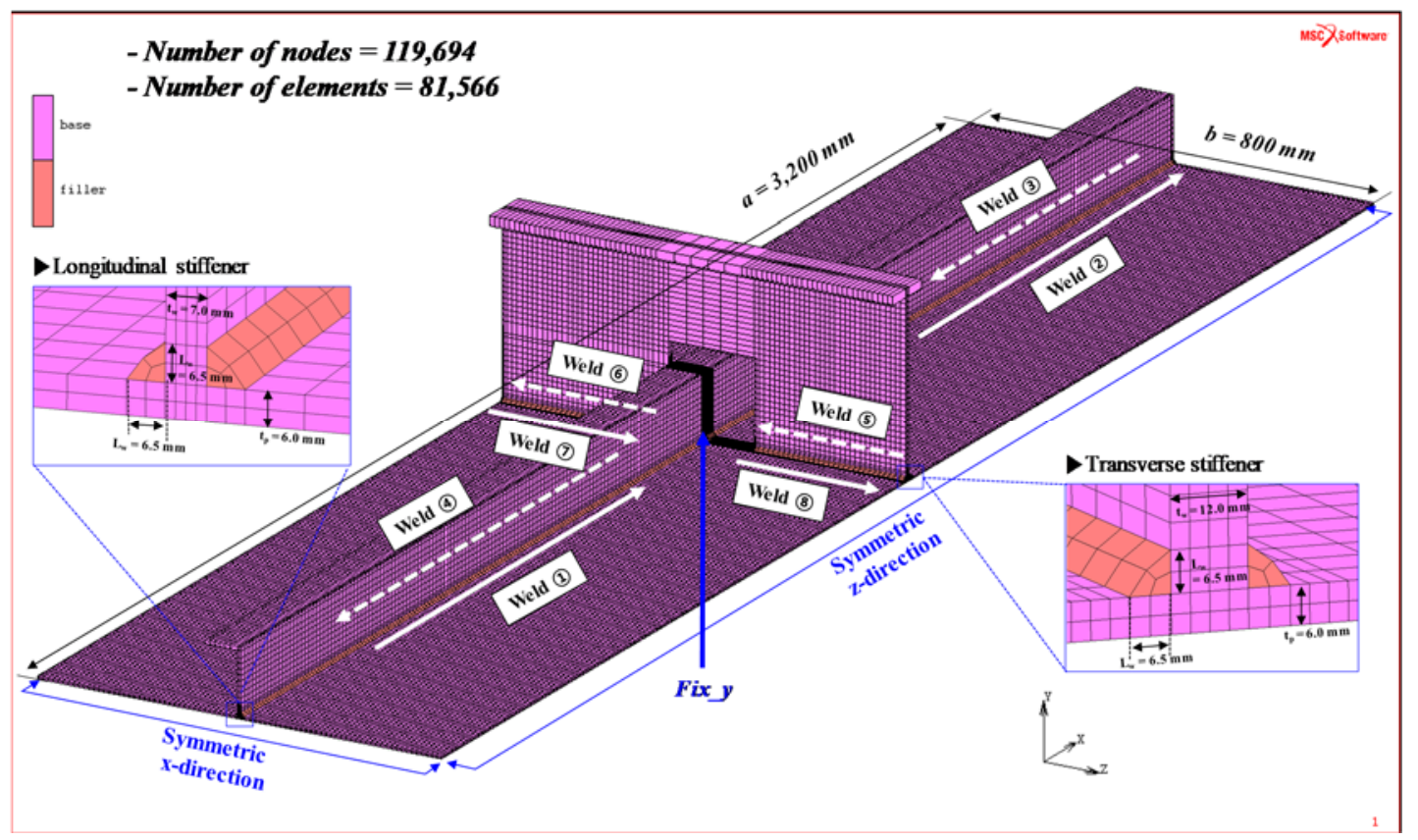

Figure 11. Thermal loading and boundary conditions for a quarter model of the object structure (Yi et al. 2018a). 


\subsection{Direct measurements}

The XRD (X-Ray Diffraction technique) was used to measure welding-induced residual stresses. Figure 12 shows a set-up for measuring such stresses. The welding-induced residual stresses, both in longitudinal and transverse directions, were measured at eight locations in each direction. All measurements using XRD were performed on the opposite side to which the stiffener is welded.

And, there is no much influence of initial residual stress before welding. Because, the nearby welded area is melted by welding heat, so it gets free from initial residual stress during this weld heat input. During the cooling process, stresses are created and only residual stresses due to welding are generated. Therefore, the vicinity of the weld is not affected by the initial residual stress due to other factor. This phenomena is well explained by previous researcher (Masubuchi, 1980). On the other hand, the residual stress at the site away from the weld is influenced by the initial residual stress, but the absolute value of the initial residual stress is very small. There are also a lot of residual stress relaxation factors such as the movement of the steel from the mill to the yard and the exposure to sunlight. Figure 13 shows the measuring locations of these welding-induced residual stresses.

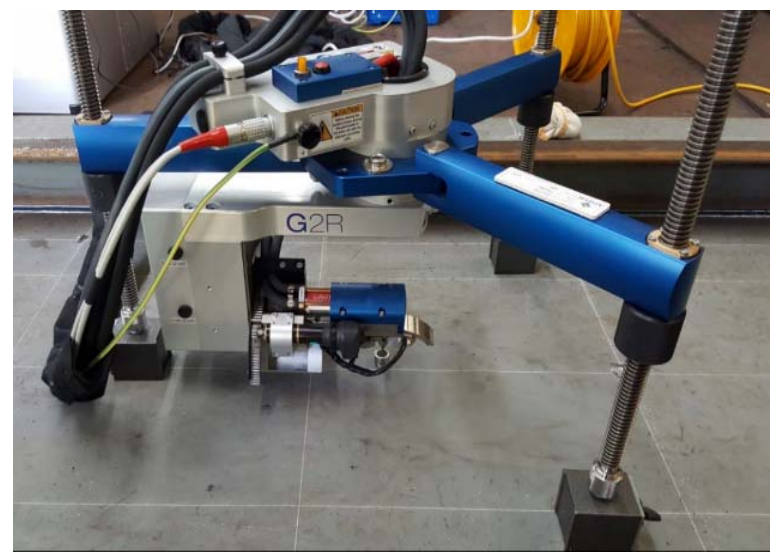

Figure 12. The set-up of the XRD (X-Ray Diffraction technique) technique to measure the weldinginduced residual stresses.

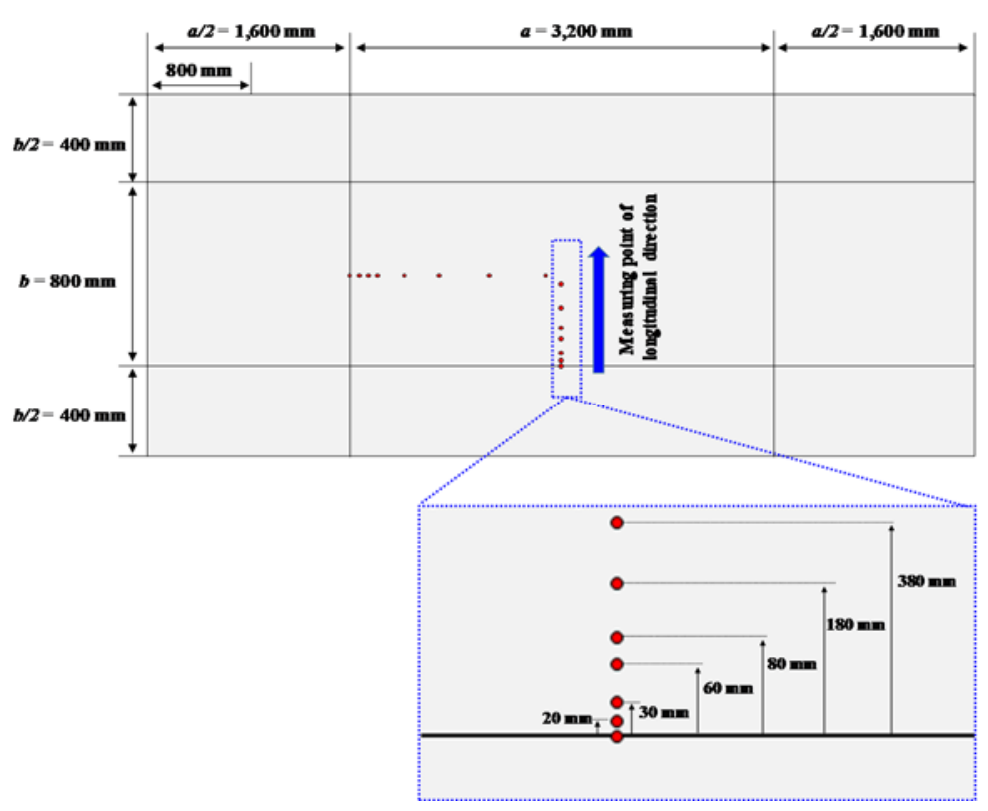


Figure 13(a). Measuring points of the welding-induced residual stresses in longitudinal directions.

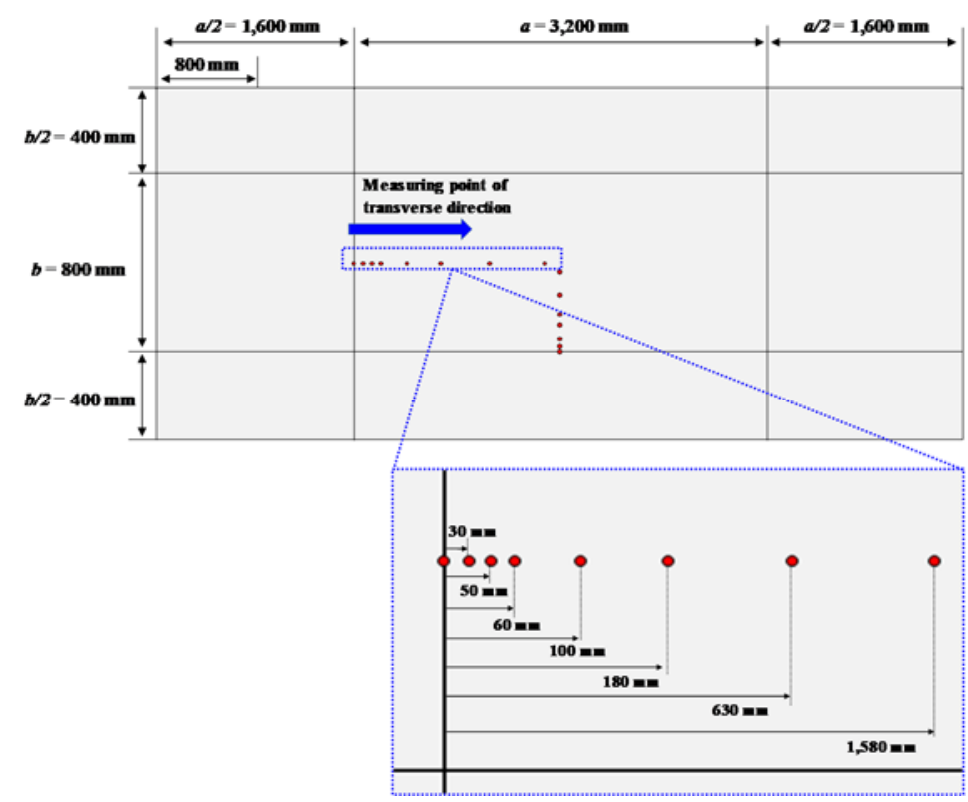

Figure 13(b). Measuring points of the welding-induced residual stresses in transverse directions.

\subsection{Distribution of welding-induced residual stresses}

Figure 14 plots the distributions of the welding-induced residual stresses in the investigated structures that were obtained from the finite element method and direct measurements. It is noted that the real shape of the tensile or compressive residual stress blocks are not exactly rectangular. Also, the XRD measurement system of the welding residual stresses involve inevitable variations that are shown in the figures with "bars". The direct measurement database was used to develop the empirical formula, while they were useful to validate the FE computations. Majority of the database used for developing the empirical formulation was obtained from the FEA.

It is shown that finite element method solutions are in good agreement with direct measurements although the former tends to underestimate compressive residual stresses compared with the latter. The zone of tensile residual stress is formed with a band width, in which the stress is approximately equal to the tensile yield stress because the molten metal can expand freely, as a liquid, whereas after welding it quickly reverts to a solid and the shrinkage that occurs during cooling involves "plastic flow".

It is observed that the magnitude of tensile residual stresses in thicker plates is slightly greater than that in thinner plates. The plate slenderness ratios can be defined as follows:

$$
\beta_{x}=\frac{b}{t} \sqrt{\frac{\sigma_{Y}}{E}}, \quad \beta_{y}=\frac{a}{t} \sqrt{\frac{\sigma_{Y}}{E}}
$$

Figure 15 shows the changes of tensile residual stresses with changes in the plate slenderness ratios and the weld leg length. Table 4 indicates the parameter of welding heat input according to the leg length. The tensile residual stresses tend to decrease as the welding leg length increases and to increase as the plate thickness decreases. 

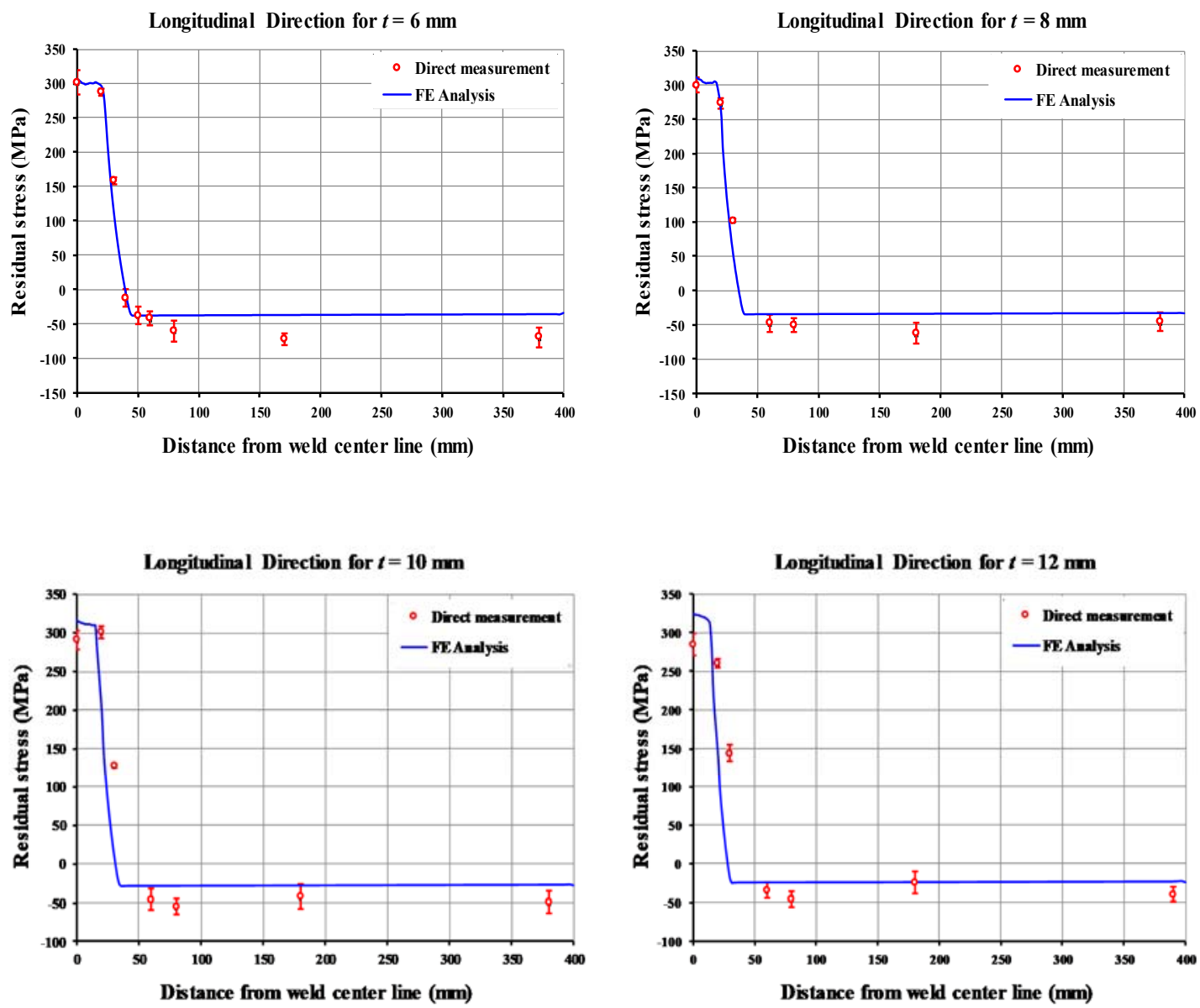

Figure 14(a). Distribution of the welding-induced residual stresses in the longitudinal direction.
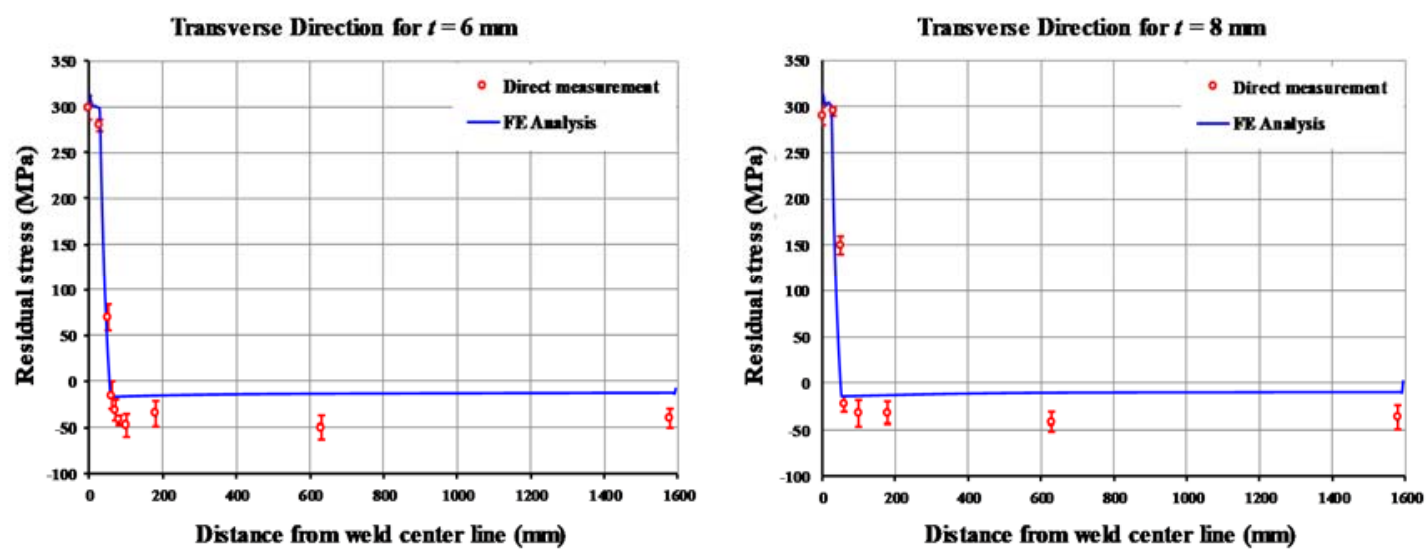

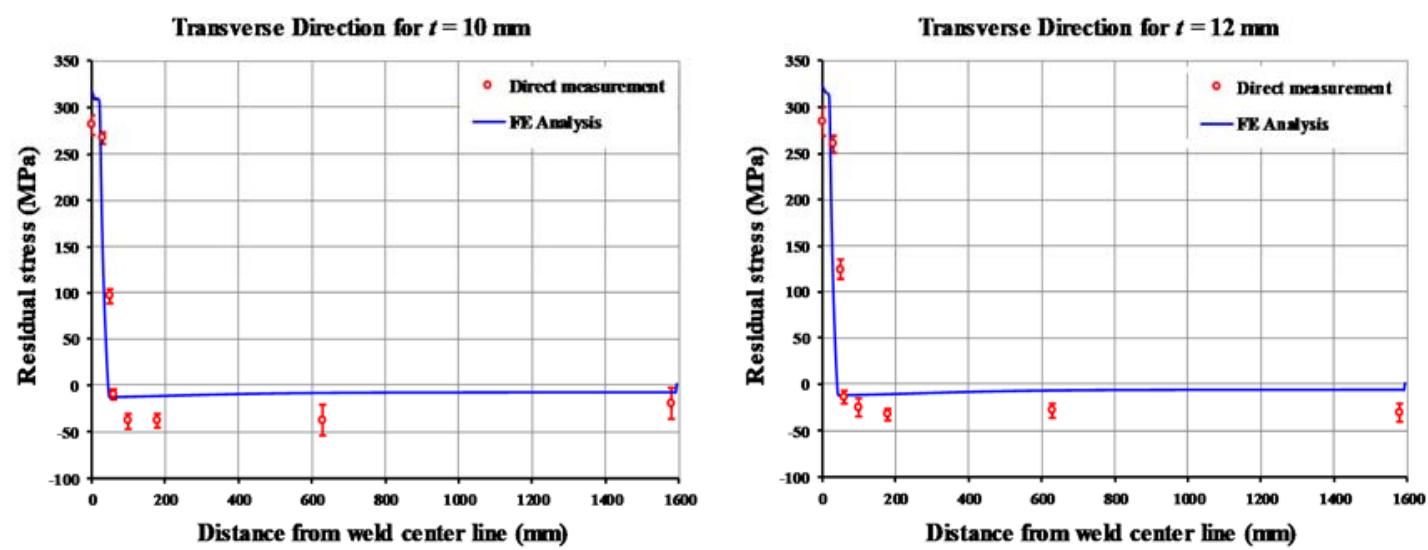

Figure 14(b). Distribution of the welding-induced residual stresses in the transverse direction.

Table 4. Parameters of welding heat input according to leg length.

\begin{tabular}{|c|c|c|c|c|c|}
\hline $\begin{array}{c}L_{w} \\
(\mathrm{~mm})\end{array}$ & $\begin{array}{c}\text { Current } \\
(\mathrm{A})\end{array}$ & $\begin{array}{c}\text { Voltage } \\
(\mathrm{V})\end{array}$ & $\begin{array}{c}\text { Speed } \\
(\mathrm{CPM})\end{array}$ & $\begin{array}{c}\text { Speed } \\
(\mathrm{mm} / \mathrm{s})\end{array}$ & $\begin{array}{c}\text { Heat input } \\
(\mathrm{kJ} / \mathrm{mm})\end{array}$ \\
\hline \hline 3.5 & 200 & 28 & 86 & 14.3 & 0.39 \\
\hline 4.5 & 300 & 32 & 70 & 11.7 & 0.82 \\
\hline 6.0 & 320 & 32 & 40 & 6.7 & 1.54 \\
\hline 6.5 & 320 & 32 & 36 & 6.0 & 1.71 \\
\hline 8.0 & 330 & 33 & 32 & 5.3 & 2.04 \\
\hline
\end{tabular}

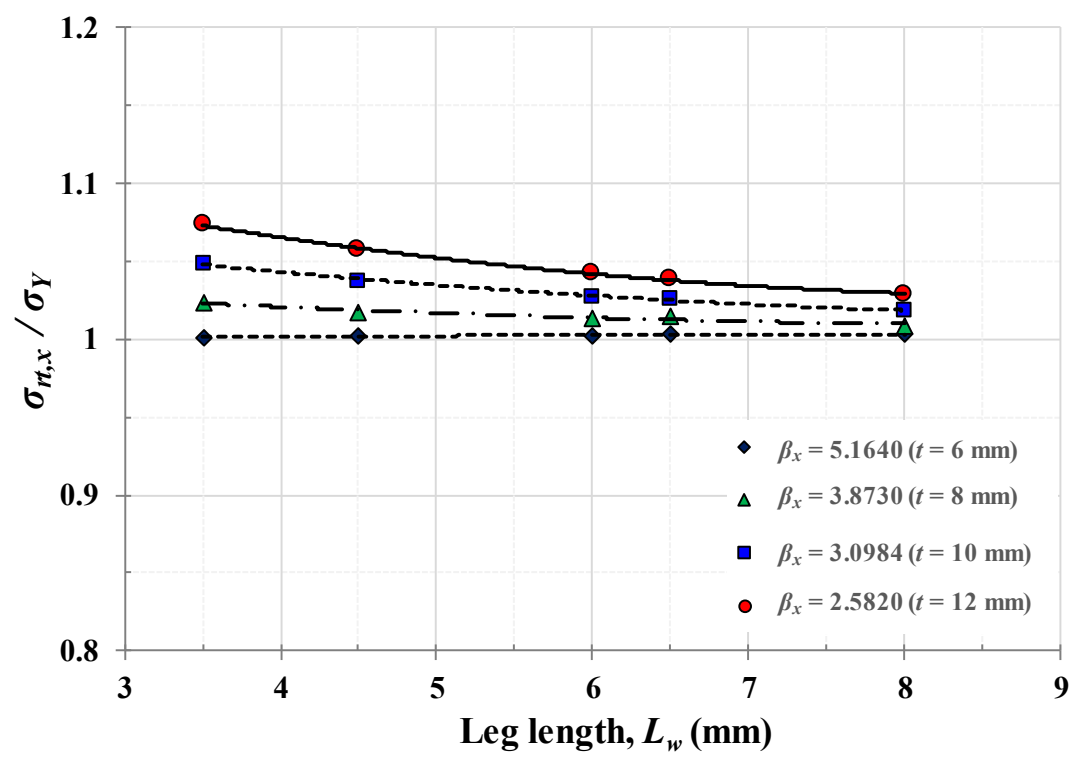

Figure 15(a). Normalized tensile residual stress versus welding leg length in the longitudinal direction. 


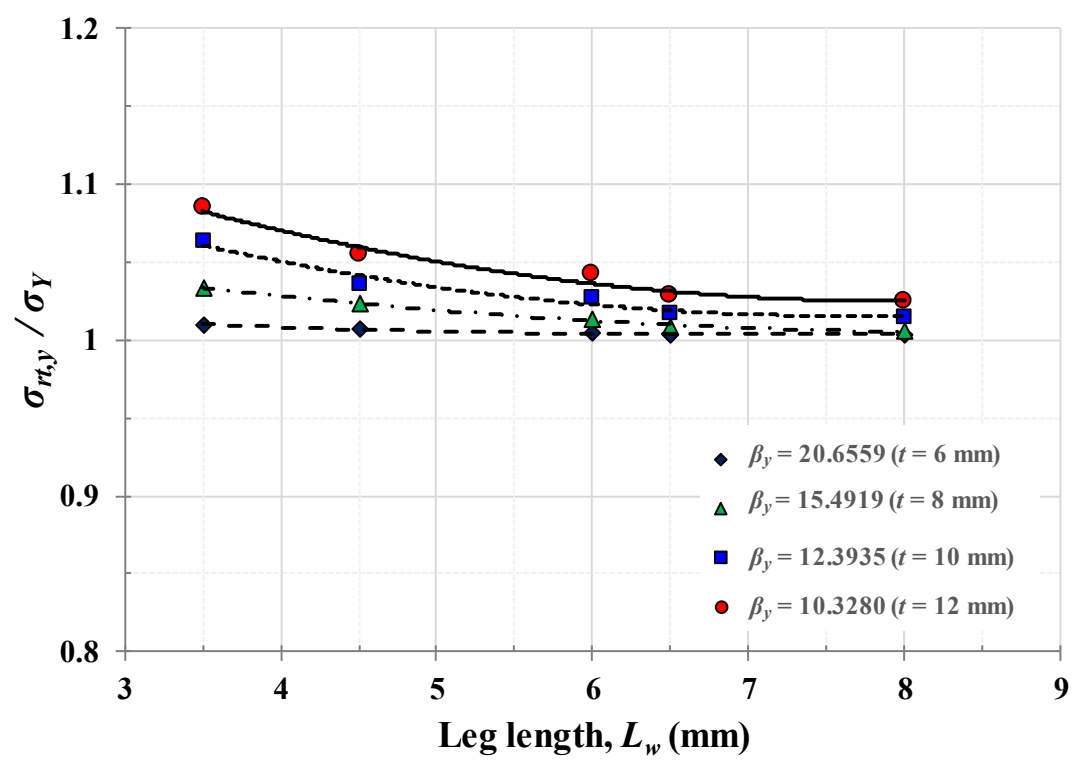

Figure 15(b). Normalized tensile residual stress versus welding leg length in the transverse direction.

\section{Derivation of an empirical formulation}

To derive the empirical formulation for predicting welding-induced residual stresses in a plate element, their distribution is modeled, as shown in Figure 6, where it is composed of tensile residual stress block and compressive residual stress block. In this case, an equilibrium condition must be satisfied between tensile and compressive residual stress blocks, thus the breadths of the tensile residual stress zone can be defined as follows (Paik 2018):

$$
2 b_{t}=\frac{\sigma_{r c x}}{\sigma_{r c x}-\sigma_{r t x}} b, 2 a_{t}=\frac{\sigma_{r c y}}{\sigma_{r c y}-\sigma_{r t y}} a
$$

Based on the databases obtained from both direct measurements and the finite element method solutions, the breadths of the tensile residual stress zone can be formulated as a function of both the plate slenderness ratio and the welding leg length as follows:

$$
b_{t}=c_{1} \times L_{w}+d_{1}
$$

where $c_{1}=-0.6212 \times \beta_{x}^{2}+5.9145 \times \beta_{x}-3.3894$ and $d_{1}=1.9505 \times \beta_{x}^{2}-16.234 \times \beta_{x}+18.711$

$$
a_{t}=c_{2} \times L_{w}+d_{2}
$$

where $c_{2}=-0.0119 \times \beta_{y}^{2}+0.5177 \times \beta_{y}+1.1372$ and $d_{2}=0.0089 \times \beta_{y}^{2}-0.1506 \times \beta_{y}-3.1284$.

Figure 16 shows the accuracy of Equations (3) and (4) in comparison with finite element method solutions, where the accuracy of the coefficients of Equations (3) and (4) are confirmed in Figure 17. 


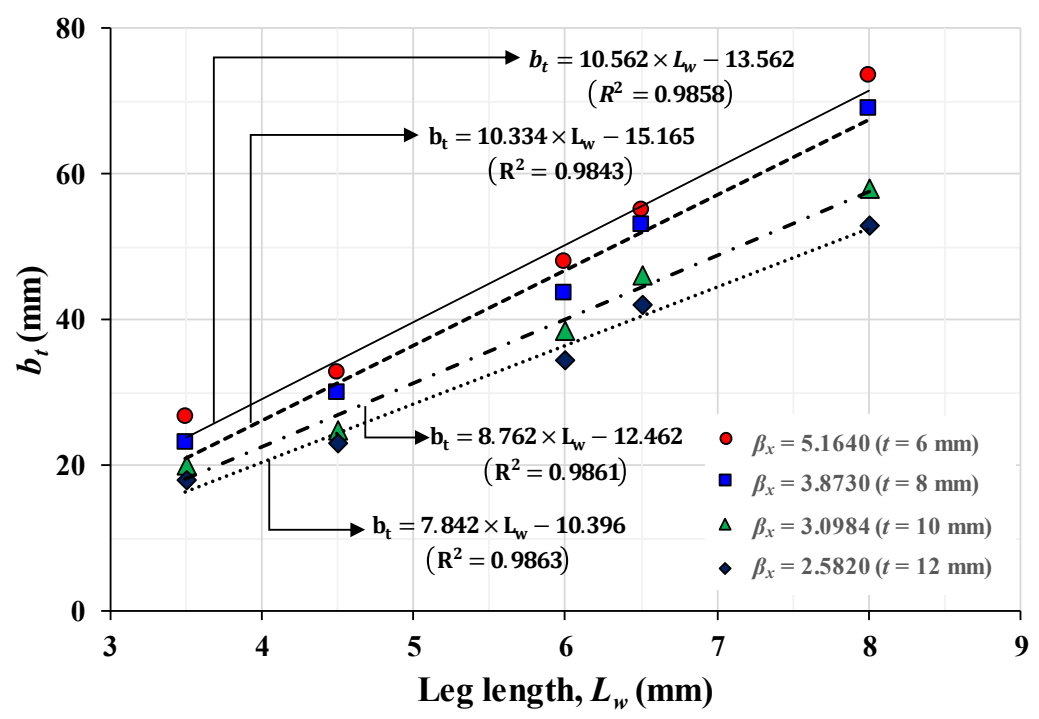

Figure 16(a). Accuracy of Equation (3) for the breadth of the tensile residual stress zone in the longitudinal direction.

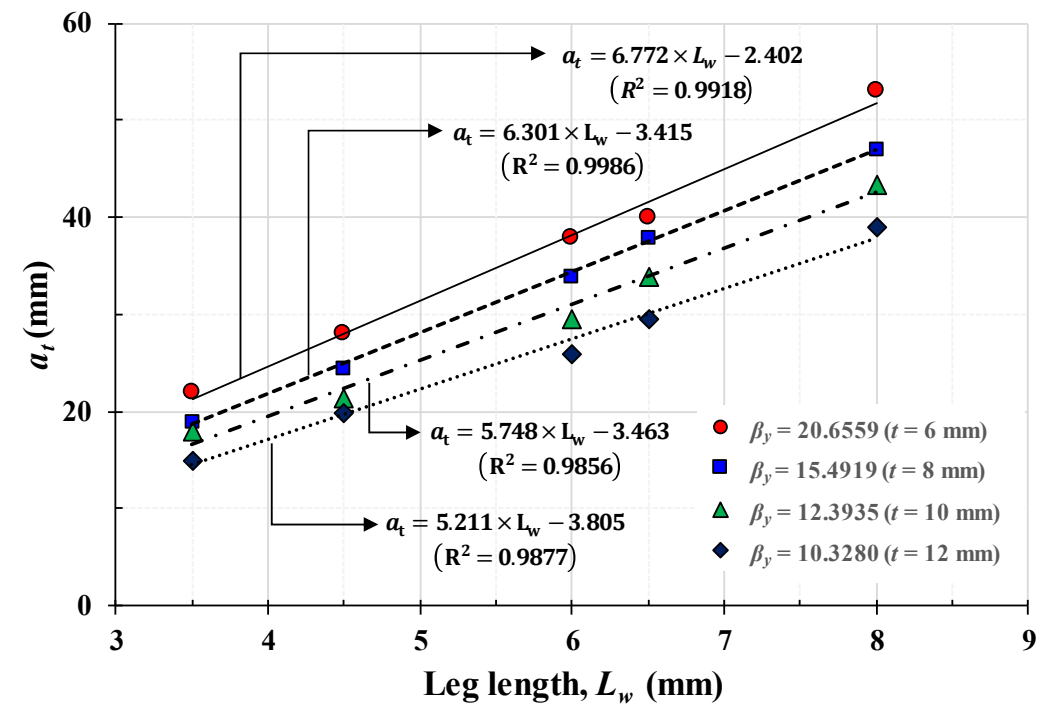

- Figure 16(b). Accuracy of Equation (4) for the breadth of the tensile residual stress zone in the transverse direction.
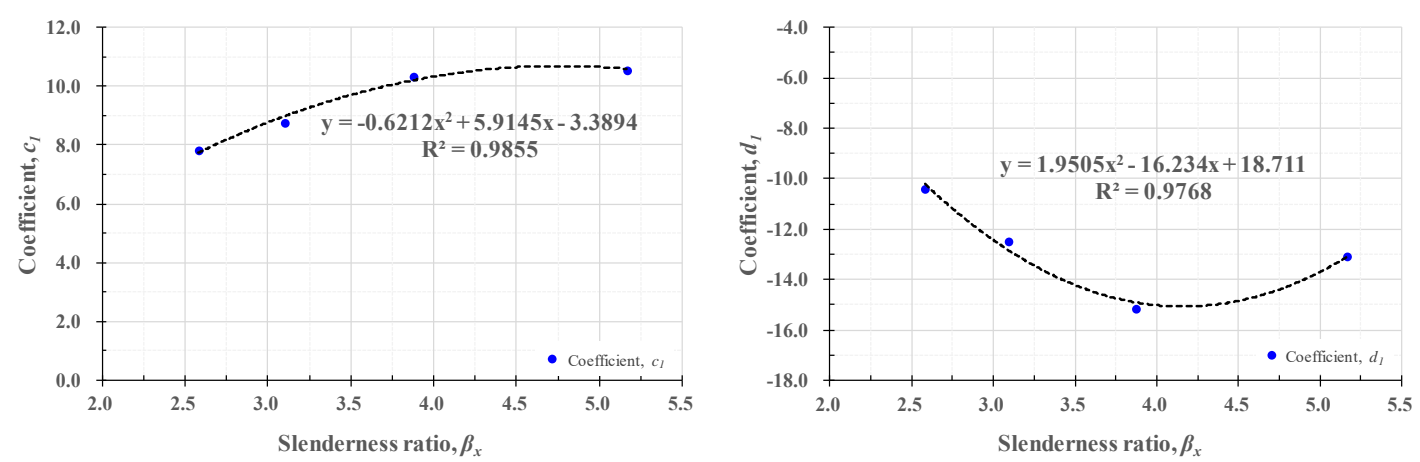

Figure 17(a). Accuracy of coefficients in Equation (3). 

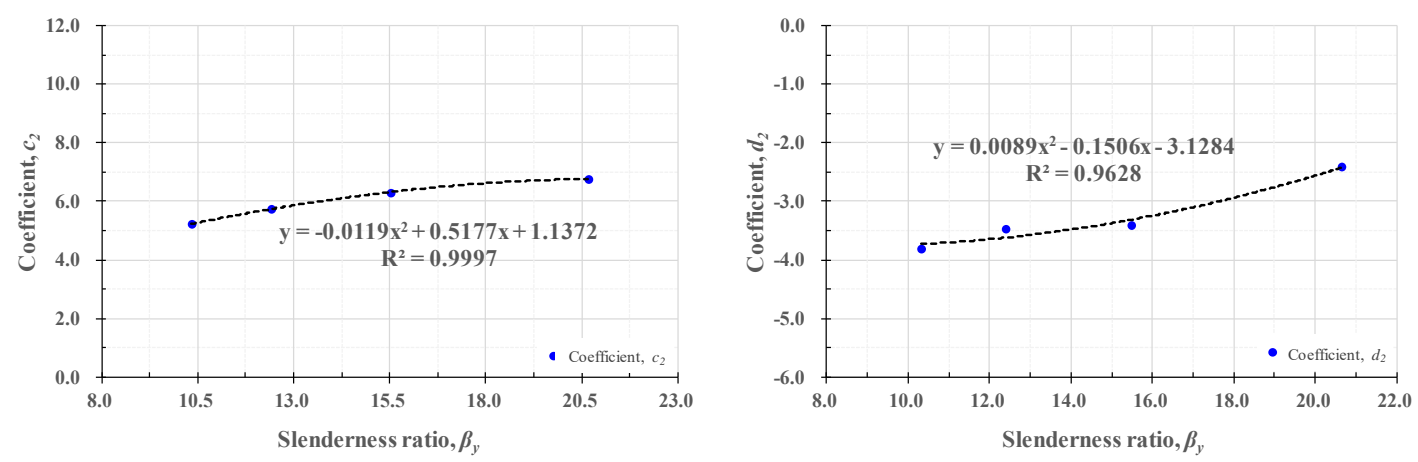

Figure 17(b). Accuracy of coefficients in Equation (4).

Once the breadths of the tensile residual stress zone are defined from Equation (3) or (4), the magnitude of compressive residual stress block can be determined from the equilibrium equations in Equation (2) as follows:

$$
\begin{gathered}
\sigma_{r c x}=\frac{2 b_{t}}{2 b_{t}-b} \times \sigma_{r t x} \\
\sigma_{r c y}=\frac{2 a_{t}}{2 a_{t}-a} \times \sigma_{r t y}
\end{gathered}
$$

where the magnitude of tensile residual stress block may be taken as $\sigma_{r t x}=\sigma_{r t y}=\sigma_{Y}$.

Figure 18 shows the statistical error assessment of Equations (5) and (6). The mean value of the deviations is 0.98 and the coefficient of variation is 0.01 .
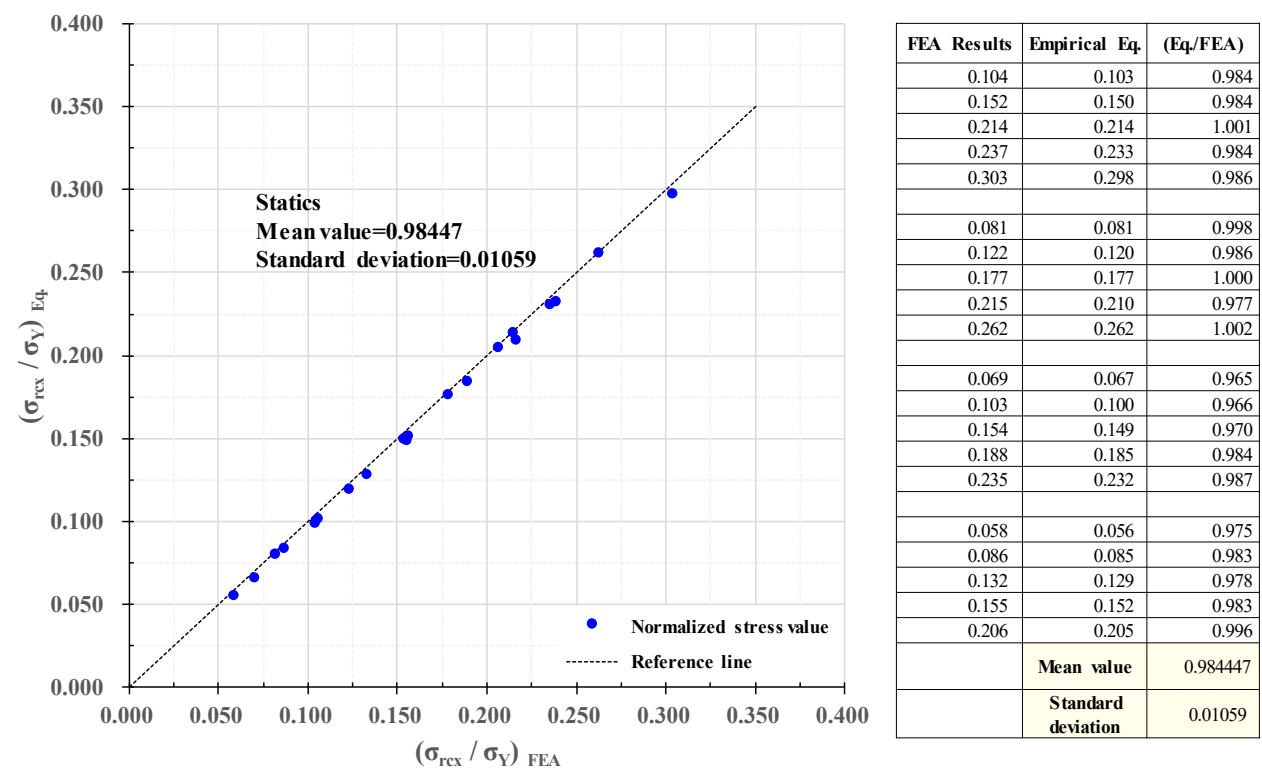

Figure 18(a). Statistical error assessment of Equation (5). 

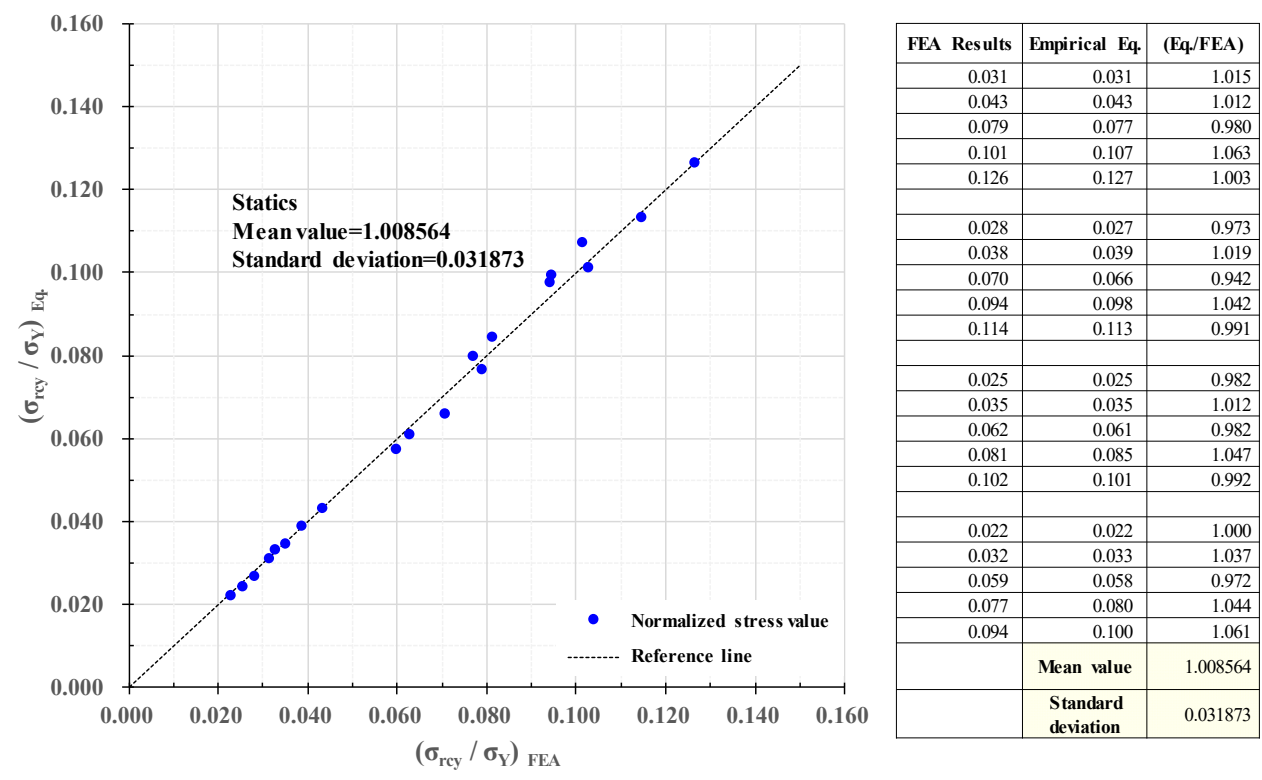

Figure 18(b). Statistical error assessment of Equation (6).

\section{GUI (Graphical User Interface) based automatic control of thermal buckling}

To make an automatic control of the thermal buckling possible, a GUI based computer program is developed. Figure 19 shows the flow of the thermal buckling control. Once welding conditions, e.g., the magnitude of weld leg length in addition to geometric and material properties of plate panels are given, the welding-induced biaxial compressive residual stress components are predicted from the proposed formula. The plate buckling strength is significantly affected by the torsional rigidities of support members as well as plate thickness, and it is predicted by closed-form expressions proposed by Paik (2018). Unless the plate buckling strength is greater than the welding-induced biaxial compressive residual stresses, the plate thermally buckles. To prevent thermal buckling, the plate buckling strength is increased by increasing the torsional rigidities of support members. It is interesting to mention that shipyards store specific types and dimensions of support members, and the computer program searches for "optimum" support members which should be minimum at weight but maximum at buckling strength, while preventing the thermal buckling. In another option, the weld bead length can also be reduced to reduce the welding-induced residual stresses as well. Figure 20 shows the front page of the GUI based computer program for thermal buckling control of plate panels.

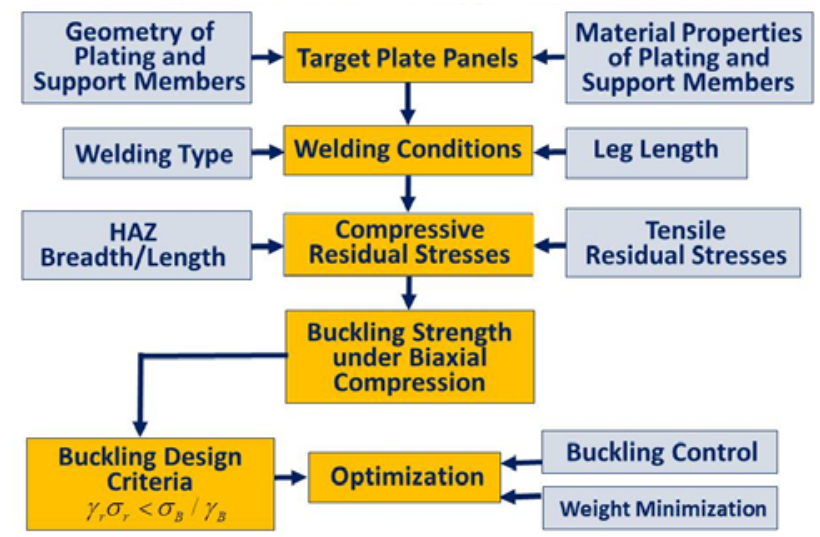

Figure 19. Flow of the thermal plate buckling control. 


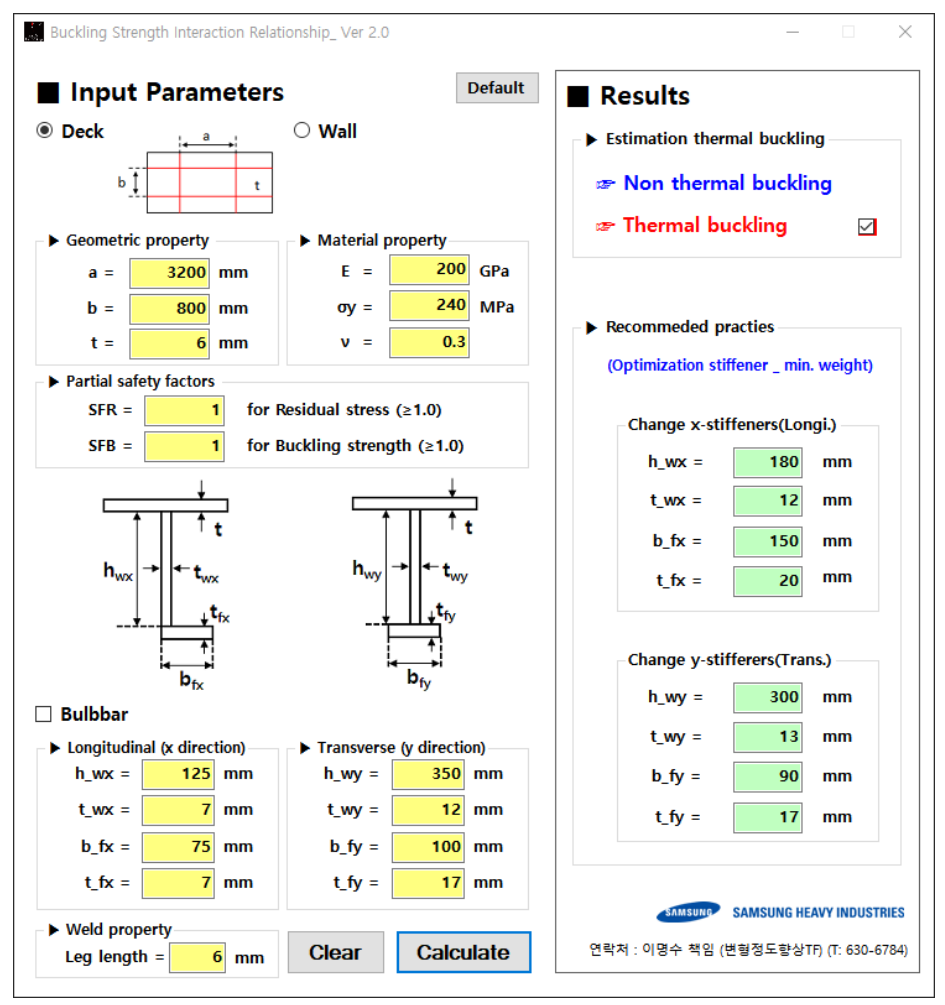

Figure 20. Front page of the GUI (Graphical User Interface) based computer program for thermal buckling control of plate panels.

\section{Application to prevention of thermal buckling}

The proposed method is now applied to thin plate panels in living quarters of offshore platforms, with a plate thickness of $6 \mathrm{~mm}$. The plate panels in typical (original) designs have attached flat bar type support members as presented in Table 6 and Figure 21, and they deflected significantly during welding process as shown in Figure 22. Table 5 presents the mechanical properties of steel used for the structures.

FB Stiffener (125x12 FB)

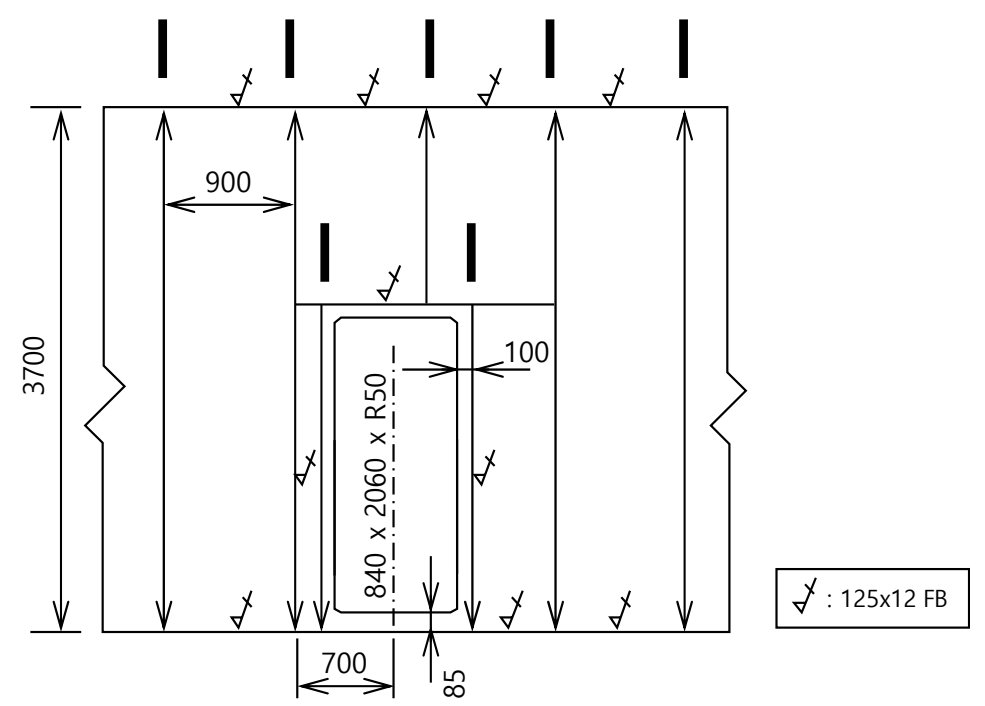

Figure 21. Typical (original) design of the target plate panel in a living quarter of an offshore platform. 


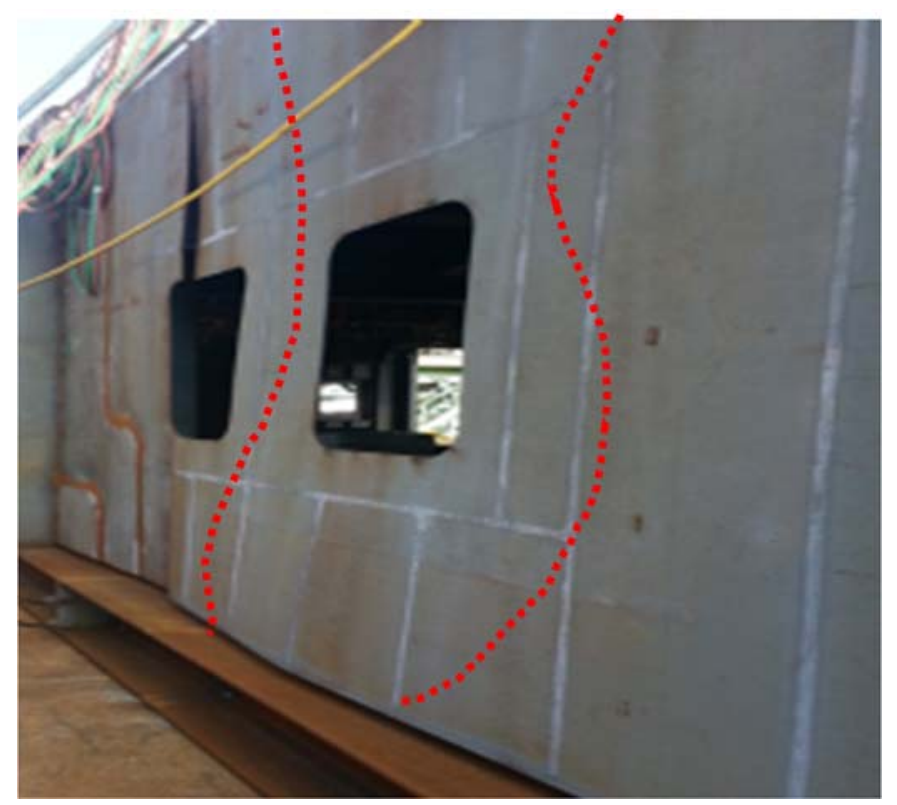

Figure 22. Thermal buckling occurred in thin plate panels with a thickness of $6 \mathrm{~mm}$.

Table 5. Nominal values of material properties used for the plate panels (obtained from POSCO steel mill certification).

\begin{tabular}{|c|c|c|c|c|c|}
\hline Kind of material & $E(\mathrm{GPa})$ & $\sigma_{Y}(\mathrm{MPa})$ & $\sigma_{u}(\mathrm{MPa})$ & $v$ & $\varepsilon_{f}(\mathrm{~mm} / \mathrm{mm})$ \\
\hline \hline Mild steel (Grade A) & 200 & 309 & 385 & 0.32 & 0.23 \\
\hline
\end{tabular}

Note: $E$ is the elastic modulus, $\sigma_{Y}$ is the yield strength, $\sigma_{u}$ is the ultimate tensile strength, $v$ is the Poisson ratio, and $\varepsilon_{f}$ is the fracture strain (elongation).

Table 6. Dimensions of the original design of the plate panel.

\begin{tabular}{|c|c|c|c|c|c|c|c|c|c|}
\hline & $\begin{array}{c}a \\
(\mathrm{~mm})\end{array}$ & $\begin{array}{c}b \\
(\mathrm{~mm})\end{array}$ & $\begin{array}{c}t \\
(\mathrm{~mm})\end{array}$ & $\begin{array}{c}L_{w} \\
(\mathrm{~mm})\end{array}$ & Stiffener Type & $\begin{array}{c}h_{w} \\
(\mathrm{~mm})\end{array}$ & $\begin{array}{c}t_{w} \\
(\mathrm{~mm})\end{array}$ & $\begin{array}{c}b_{f} \\
(\mathrm{~mm})\end{array}$ & $\begin{array}{c}t_{f} \\
(\mathrm{~mm})\end{array}$ \\
\hline \multirow{2}{*}{$\begin{array}{l}\text { Original } \\
\text { Design }\end{array}$} & \multirow{2}{*}{3,700} & \multirow{2}{*}{900} & \multirow{2}{*}{6} & \multirow{2}{*}{6} & $\begin{array}{l}\text { Longitudinal } \\
\text { (FB type) }\end{array}$ & 125 & 12 & 0 & 0 \\
\hline & & & & & $\begin{array}{l}\text { Transverse } \\
\text { (FB type) }\end{array}$ & 125 & 12 & 0 & 0 \\
\hline \multirow{2}{*}{$\begin{array}{c}\text { Modified } \\
\text { Design }\end{array}$} & \multirow{2}{*}{3,700} & \multirow{2}{*}{900} & \multirow{2}{*}{6} & \multirow{2}{*}{6} & $\begin{array}{l}\text { Longitudinal } \\
\text { (L2 type) }\end{array}$ & 125 & 8 & 100 & 12 \\
\hline & & & & & $\begin{array}{l}\text { Transverse } \\
\text { (FB type) }\end{array}$ & 125 & 12 & 0 & 0 \\
\hline
\end{tabular}




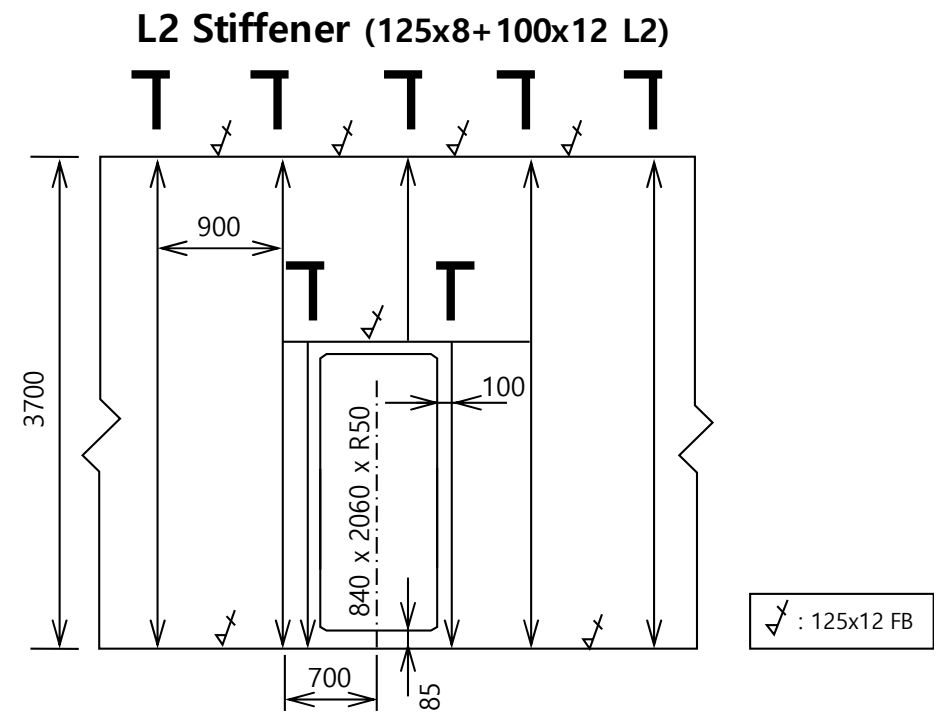

Figure 23. Modified design of the target plate panel.

The GUI based computer program searched for the optimum (modified) design of support members which is presented in Table 5 and Figure 23. In the following, the outcome of the design optimization is analyzed.

When the longer direction of the plate panel is taken as the $x$ direction, the plate slenderness ratios are calculated from Equation (1) as follows:

$$
\beta_{x}=5.89, \beta_{y}=24.24
$$

The welding leg length applied for building the structures is $L_{w}=6.0 \mathrm{~mm}$, and thus the breadths of the tensile residual stress zones can be defined from Equations (3) and (4) as follows:

$$
b_{t}=50.13 \mathrm{~mm}, a_{t}=38.62 \mathrm{~mm}
$$

Therefore, the compressive residual stresses developed in the plate panels can be estimated from Equations (5) and (6) as follows:

$$
\sigma_{r c x}=-38.74 \mathrm{MPa}, \quad \sigma_{r c y}=-6.59 \mathrm{MPa}
$$

Under biaxial compressive loading, the elastic buckling strength interaction relationship is given as follows (Paik 2018):

$$
\left(\frac{\sigma_{x}}{\sigma_{x E, 1}}\right)^{\alpha_{1}}+\left(\frac{\sigma_{y}}{\sigma_{y E, 1}}\right)^{\alpha_{2}}=1
$$

where,

$$
\begin{aligned}
& \left.\begin{array}{l}
\alpha_{1}=\alpha_{2}=1 \quad \text { for } 1 \leq a / b \leq \sqrt{2} \\
\alpha_{1}=0.0293\left(\frac{a}{b}\right)^{3}-0.3364\left(\frac{a}{b}\right)^{2}+1.5854\left(\frac{a}{b}\right)-1.0596 \\
\alpha_{2}=0.0049\left(\frac{a}{b}\right)^{3}-0.1183\left(\frac{a}{b}\right)^{2}+0.6153\left(\frac{a}{b}\right)+0.8522
\end{array}\right\} \text { for } a / b>\sqrt{2}
\end{aligned}
$$

In Equation (10), $\sigma_{x E, 1}$ and $\sigma_{y E, 1}$ are the buckling strengths of the plate under uniaxial axial 
compressive load in the $x$ and $y$ directions, respectively, which are defined by

$$
\sigma_{x E, 1}=k_{x} \frac{\pi^{2} E}{12\left(1-v^{2}\right)}\left(\frac{t}{b}\right)^{2}, \quad \sigma_{y E, 1}=k_{y} \frac{\pi^{2} E}{12\left(1-v^{2}\right)}\left(\frac{t}{b}\right)^{2}
$$

In Equation (11), $k_{x}$ and $k_{y}$ are the buckling coefficients of the elastic buckling strengths under uniaxial compressive loading in the $x$ and $y$ directions, respectively, which can be obtained by taking account of the rotational restraint effects associated with torsional rigidity of support members (stiffeners) as follows (Paik 2018):

$$
k_{x}=k_{x 1}+k_{x 2}-k_{x 0}, k_{y}=k_{y 1}+k_{y 2}-k_{y 0}
$$

where,

$k_{x}=$ buckling coefficient of the plate elastically rotation-restrained at both the long and short edges,

$k_{x 1}=$ buckling coefficient of the plate elastically rotation-restrained at the long edges and simply supported at the short edges,

$k_{x 2}=$ buckling coefficient of the plate elastically rotation-restrained at the short edges and simply supported at the long edges,

$k_{x 0}=$ buckling coefficient of the plate simply supported at all edges,

$k_{y}=$ buckling coefficient of the plate elastically rotation-restrained at both the long and short edges,

$k_{y 1}=$ buckling coefficient of the plate elastically rotation-restrained at the long edges and simply supported at the short edges,

$k_{y 2}=$ buckling coefficient of the plate elastically rotation-restrained at the short edges and simply supported at the long edges, and

$k_{y 0}=$ the buckling coefficient of the plate simply supported at all edges.

The buckling coefficients in Equation (12) are a function of the rotational restraint parameters that are dependent on the torsional rigidities of the support members, where the rotational restraint parameters are defined as follows (Paik 2018):

$$
\zeta_{L}=\frac{G J_{L}}{b D}, \zeta_{S}=\frac{G J_{S}}{a D}
$$

where $G=\frac{E}{2(1+v)}, D=\frac{E t^{3}}{12\left(1-v^{2}\right)}, \quad J_{L}=\frac{h_{w x} t_{w x}^{3}+b_{f x} t_{f x}^{3}}{3}$, and $J_{S}=\frac{h_{w y} t_{w y}^{3}+b_{f y} t_{w y}^{3}}{3}$.

For the original design, $\zeta_{L}=1.19$ and $\zeta_{S}=0.38$, and thus the buckling coefficients of plate panels, taking into account the effect of rotational restraints, are calculated as follows:

$$
k_{x}=k_{x 1}+k_{x 2}-k_{x 0}=6.12+4.19-4.0=6.31, \quad k_{y}=k_{y 1}+k_{y 2}-k_{y 0}=1.38+1.13-1.12=1.39
$$

The buckling strengths of the original plate under uniaxial compressive residual stresses are calculated from Equation (11) as follows:

$$
\sigma_{x E, 1}=-50.74 \mathrm{MPa}, \sigma_{y E, 1}=-11.20 \mathrm{MPa}
$$

In contrast, the values of the rotational restraint parameters for the modified design are calculated as $\zeta_{L}=1.71$ and $\zeta_{S}=0.38$ because a L2 type stiffener that was determined by the design optimization is now used instead of the flat bar used for the original design. Therefore, the buckling coefficients of plate panels, taking into account the effect of rotational restraints, are now calculated as follows:

$$
k_{x}=k_{x 1}+k_{x 2}-k_{x 0}=6.30+4.20-4.0=6.50, k_{y}=k_{y 1}+k_{y 2}-k_{y 0}=1.49+1.13-1.12=1.50
$$


The buckling strengths of the modified plate under uniaxial compressive residual stresses are calculated from Equation (11) as follows:

$$
\sigma_{x E, 1}=-52.23 \mathrm{MPa}, \sigma_{y E, 1}=-12.02 \mathrm{MPa}
$$

Equations (13) and (14) show that the elastic buckling strengths are increased by $2.9 \%$ and $7.3 \%$ in the $x$ and $y$ directions, respectively. Figure 24 ascertains that the modified design of the target plate panel can prevent thermal buckling because the welding-induced compressive residual stress components in the $x$ and $y$ directions can be controlled inside the buckling strength interaction relationship, while the original design presents them outside of that relationship, thus causing thermal buckling. It is noted that the increase of the support members' scantlings was minimized for the minimization of weight or building coast as far as the thermal buckling is prevented. Figure 25 presents the deformation of the plate panels with modified designs after welding. It is proven from Figure 25 that the modification of plate panels designs almost prevented welding-induced distortions, and the proposed method is very useful for preventing thermal plate buckling. Fairing works were then minimized by the modified designed as shown in Figure 26.

Figure 27 shows the vessel $\left(174 \mathrm{~km}^{3}\right.$ class LNG carrier) recently constructed at the yard of Samsung Heavy Industries Co., Ltd. where the present technology has been applied. After application of this present technology, the thermal buckling did not occur and there were very few additional modifications to the doorframe.

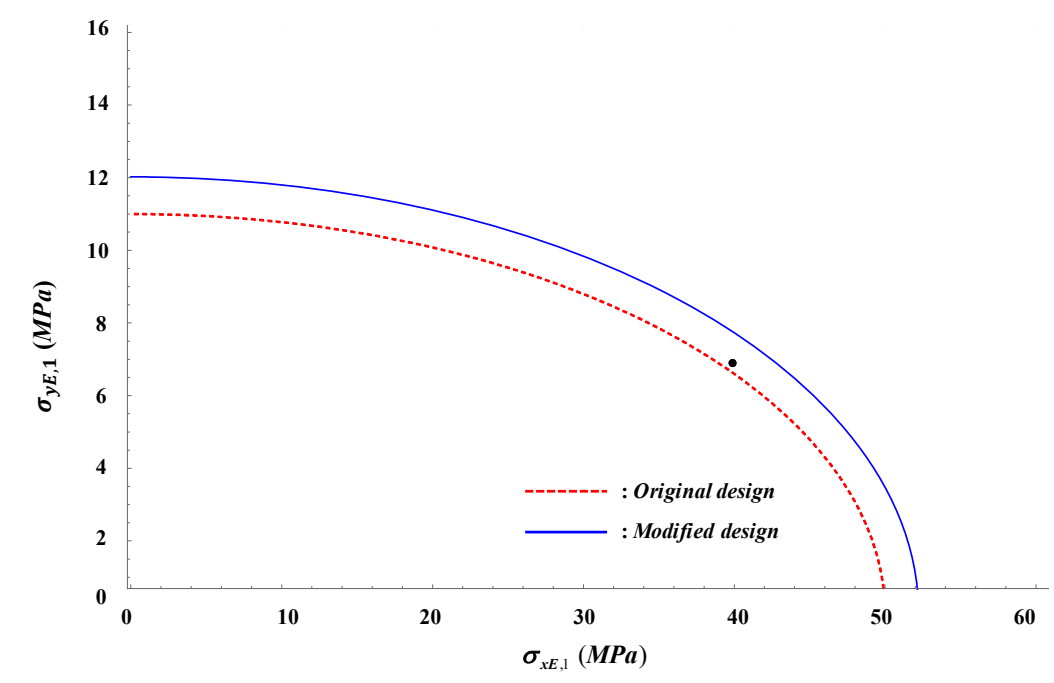

Figure 24. Elastic buckling strength interaction relationship of the plate panel under combined welding-induced compressive residual stresses in the $x$ and $y$ directions.
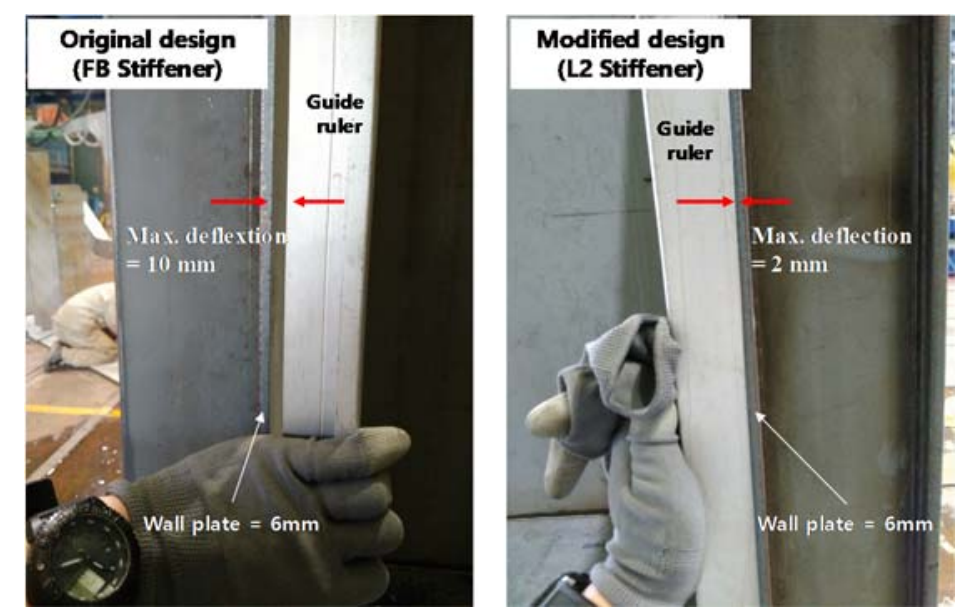

Figure 25. Distortion of the door frames due to welding in the original versus modified designs for the target plate panel. 

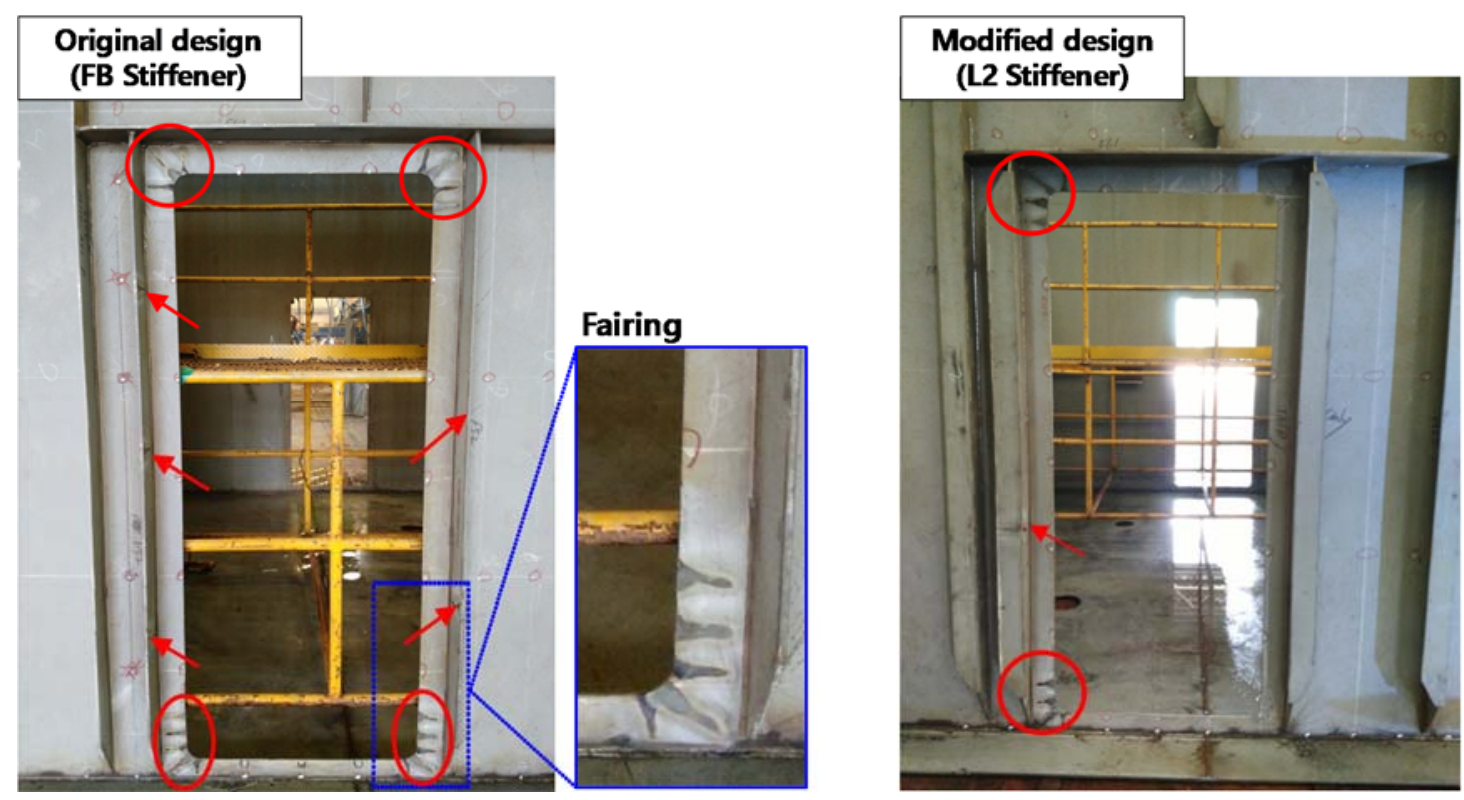

Figure 26. Fairing work of the doorframes to remove the welding-induced deflections for the original versus modified designs of the target plate panel.
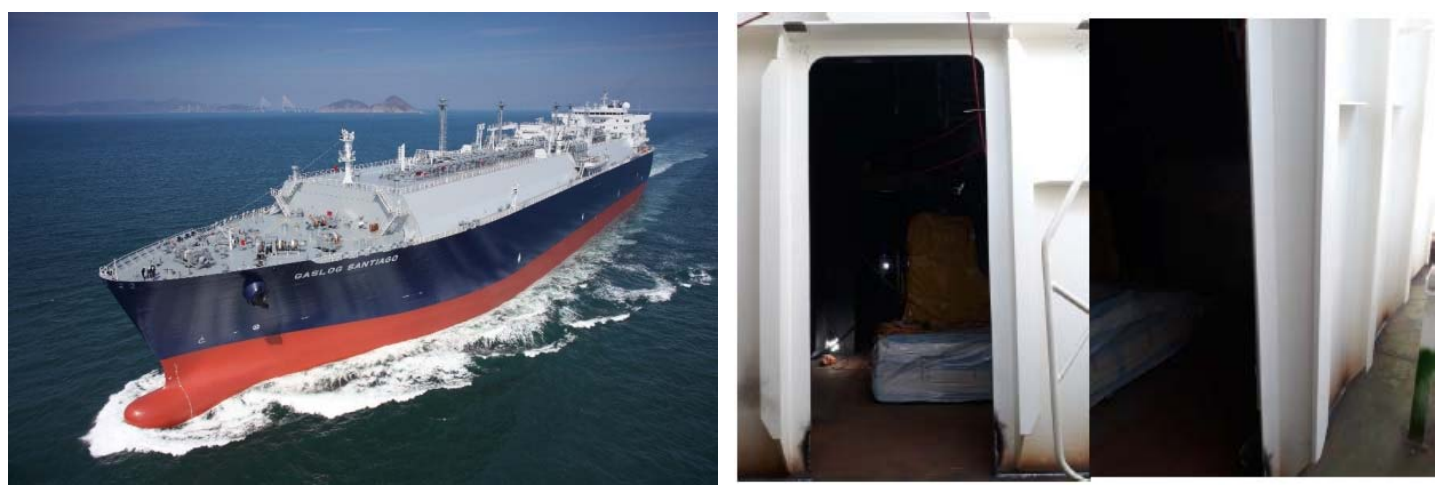

Figure 27. The vessel (174 $\mathrm{km}^{3}$ class LNG carrier) constructed at the yard of Samsung Heavy Industries Co., Ltd. where the present technology has been applied.

\section{Concluding remarks}

The background of the present study has been to develop an innovative technology for preventing thermal buckling of thin plate panels during welding process. This paper focuses on deriving an empirical formulation for predicting welding-induced residual stresses in steel plated structures, which cause the thermal plate buckling. The application of the formula may be limited to thin plate panels with a thickness of 6-12 mm welded by arc welding. The databases for welding-induced residual stresses on full-scale models of steel stiffened plate structures were obtained from direct measurements and finite element method computations. The developed technologies have been applied to real problems in shipyards. Based on this study, the following conclusions can be drawn.

(1) As well recognized, welding-induced residual stresses develop in both longitudinal and transverse directions because support members are attached in the two directions.

(2) The distributions of welding-induced residual stresses are composed of both tensile residual stresses in the near welding zone and compressive residual stresses in the middle of the plate. 
(3) The magnitude of the tensile residual stresses in the near welding zone reaches the yield stress of the material.

(4) As weld leg length increases, the breadths of the tensile residual stress zone increases while the magnitude of the tensile residual stresses in the breadths of the tensile residual stress zone tends to decrease.

(5) The breadths of the tensile residual stress zone can be formulated as a function of plate thickness and weld leg length. From the equilibrium between tensile and compressive residual stresses, the magnitude of compressive residual stresses can then be determined once the breadths of the tensile residual stress zone are defined where the magnitude of tensile residual stresses is assumed to equal the yield stress of material.

(6) As an applied example, the developed formulations were applied to prevent the thermal buckling of thin plate panels that are part of living quarters of an offshore platform.

(7) It is concluded that the developed formulations can be useful for predicting the weldinginduced residual stresses developed in both longitudinal and transverse directions.

\section{Acknowledgement}

The present study was undertaken at the Korea Ship and Offshore Research Institute (The International Centre for Advanced Safety Studies) at Pusan National University which has been a Lloyd's Register Foundation Research Centre of Excellence since 2008.

\section{References}

Bruno, G., Yordan. G. \& Guedes Soares, C. (2011). Effect of weld shape imperfections on the structural hot-spot stress distribution, Ships and Offshore Structures, 6(1-2): 145-159.

Chen, B.Q., Hashemzadeh, M. \& Guedes Soares, C. (2018). Validation of numerical simulations with X-ray diffraction measurements of residual stress in butt-welded steel plates, Ships and Offshore Structures, 13(3): 273-282.

Cheng, J.J.R., Elwi, A.E., Grodin, G.Y. \& Kulak, G.L. (1996). Material testing and residual stress measurements in a stiffened steel plate. In: Strength and Stability of Stiffened Plate Components. Ship Structure Committee, SSC-399, Washington, DC.

Eggert, L., Fricke, W. \& Paetzhold, H. (2012). Fatigue strength of thin-plated block joints with typical shipbuilding imperfections. Welding in the World, 56(11-12): 119-128.

Farajkhah, V., Liu, Y. \& Gannon, L. (2016). Finite element study of 3D simulated welding effect in aluminium plates, Ships and Offshore Structures, 12(2): 196-208.

Gannon, L.G., Liu, Y., Pegg, N.G. \& Smith, M.J. (2012a). Effect of three-dimensional weldinginduced residual stress and distortion fields on strength and behaviour of flat-bar stiffened panels, Ships and Offshore Structures, 8(5): 565-578.

Gannon, L.G., Pegg, N.G., Smith, M.J. \& Liu, Y. (2012b). Effect of residual stress shakedown on stiffened plate strength and behaviour, Ships and Offshore Structures, 8(6): 638-652.

Gannon, L., Liu, Y., Pegg, N. \& Smith, M.J. (2015). Nonlinear collapse analysis of stiffened plates considering welding-induced residual stress and distortion, Ships and Offshore Structures, 11(3): 228-244.

Kavanagh, B.F. \& Glenn Bird, S.J. (1996). Surveying principles and applications (4 ed.). Prentice Hall, pp. 257-264. 
Kenno, S.Y., Das, S., Kennedy J, Rogge, R. \& Gharghouri, M. (2010). Distributions of residual stresses in stiffened plates with one and two stiffeners, Ships and Offshore Structures, 5(3): 211225.

Kenno, S.Y., Das, S., Rogge, R.B. \& Gharghouri, M. (2017). Changes in residual stresses caused by an interruption in the weld process of ships and offshore structures, Ships and Offshore Structures, 12(3): 341-359.

Khan, I. \& Zhang, S. (2011). Effects of welding-induced residual stress on ultimate strength of plates and stiffened panels, Ships and Offshore Structures, 6(4): 297-309.

Khedmati, M.R., Pedram, M. \& Rigo, P. (2012). The effects of geometrical imperfections on the ultimate strength of aluminium stiffened plates subject to combined uniaxial compression and lateral pressure, Ships and Offshore Structures, 9(1): 88-109.

Lillemäe, I., Liinalampi, S., Remes, H., Itävuo, A. \& Niemelä, A. (2017). Fatigue strength of thin laserhybrid welded full-scale deck structure, International Journal of Fatigue, 95: 282-292.

Luís, R.M., Soares, C.G. \& Nikolov, P.I. (2009). Collapse strength of longitudinal plate assemblies with dimple imperfections, Ships and Offshore Structures, 3(4): 359-370.

Masubuchi, K. (1980). Analysis of welded structures: Residual stresses, distortion and their consequences. Pergamon Press, England \& Oxford, U.K.

Matsui, S. (1983). Control of weld distortion in thin-skin welded structures, Journal of Welding and Joining, 53(5): 58-66.

MSC (2013). Online User's Guide. MSC Software Corporation, California, USA

Paik, J.K. (2007a). Practical techniques for finite element modeling to simulate structural crashworthiness in ship collisions and grounding (Part I: Theory), Ships and Offshore Structures, 2(1): 69-80.

Paik, J.K. (2007b). Practical techniques for finite element modeling to simulate structural crashworthiness in ship collisions and grounding (Part II: Verification), Ships and Offshore Structures, 2(1): 81-85.

Paik, J.K. (2007c). Characteristics of welding induced initial deflections in welded aluminum plates, Thin-Walled Structures, 45: 493-501.

Paik, J.K. (2008). Mechanical collapse testing on aluminum stiffened panels for marine applications. Ship Structure Committee, SSC-451, Washington, DC.

Paik, J.K. (2018). Ultimate limit state analysis and design of plated structures. Second Edition, John Wiley \& Sons Chichester, UK.

Paik, J.K., Andrieu, C. \& Cojeen, H.P. (2008). Mechanical collapse testing on aluminum stiffened plate structures for marine applications, Marine Technology, 45(4): 228-240.

Paik, J.K. \& Frieze, P.A. (2001). Ship structural safety and reliability, Progress in Structural Engineering and Materials, 3: 198-210.

Paik, J.K. \& Kim, D.K. (2012). Advanced method for the development of an empirical model to predict time-dependent corrosion wastage, Corrosion Science, 63: 51-58.

Paik, J.K., Kim, K.J., Lee, J.H., Jung, B.G. \& Kim, S.J. (2017). Test database of the mechanical properties of mild, high-tensile and stainless steel and aluminum alloy associated with cold temperatures and strain rates, Ships and Offshore Structures, 12(sup1): 1-27.

Paik, J.K., Kim, B.J., Sohn, J.M., Kim, S.H., Jeong, J.M. \& Park, J.S. (2012). On buckling collapse of a fusion-welded aluminum stiffened plate structure: An experimental and numerical study, Journal of Offshore Mechanics and Arctic Engineering, 134: 021402.1-8. 
Paik, J.K., Lee, J.M., Hwang, J.S. \& Park, Y.I. (2003a). A time-dependent corrosion wastage model for the structures of single- and double-hull tankers and FSOs and FPSOs, Marine Technology, 40(3): 201-217.

Paik, J.K. \& Melchers, R.E. (2008). Condition assessment of aged structures. CRC Press, New York.

Paik, J.K. \& Pedersen, P.T. (1996). A simplified method for predicting the ultimate compressive strength of ship panels, International Shipbuilding Progress, 43: 139-157.

Paik, J.K. \& Thayamballi, A.K. (2007). Ship-shaped offshore installations: Design, building, and operation. Cambridge University Press, Cambridge.

Paik, J.K., Thayamballi, A.K., Park, Y.I. \& Hwang, J.S. (2003). A time-dependent corrosion wastage model for bulk carrier structures, International Journal of Maritime Engineering, 145(A2): 61-87.

Paik, J.K., Thayamballi, A.K., Ryu, J.Y., Jang, J.H., Seo, J.K., Park, S.W., Seo, S.K., Andrieu, C., Cojeen, H.P. \& Kim, N.I. (2006). The statistics of weld induced initial imperfections in aluminum stiffened plate structures for marine applications, International Journal of Maritime Engineering, 148(Part A1): 19-63.

Paik, J.K. \& Yi, M.S. (2016). Experimental and Numerical Investigations of Welding-Induced Distortions and Stresses in Steel Stiffened Plate Structures. The Korea Ship and Offshore Research Institute, Pusan National University, Busan, South Korea.

Smith, C.S., Davidson, P.C., Chapman, J.C. \& Dowling, P.J. (1988). Strength and stiffness of ships' plating under in-plane compression and tension, Transactions of the Royal Institution of Naval Architects, 130: 277-296.

Teresa, M. \& Craig, F. (2013). Effect of weld-induced imperfections on the ultimate strength of an aluminium patrol boat determined by the ISFEM rapid assessment method, Ships and Offshore Structures, 9(2): 218-235.

Ueda, Y. (1999). Computational Welding Mechanics (A volume of selected papers in the commemoration of the retirement from Osaka University). Joining and Welding Research Institute, Osaka University, Osaka, Japan.

Vhanmane, S. \& Bhattacharya, B. (2008). Estimation of ultimate hull girder strength with initial imperfections, Ships and Offshore Structures, 3(3): 149-158.

Wang, J., Han, J., Domblesky, J.P., Li, W., Yang, Z. \& Zhao. Y. (2015). Predicting distortion in butt welded plates using an equivalent plane stress representation based on inherent shrinkage volume, Journal of Manufacturing Science and Engineering, 138(1): 011012.

Xstress 3000 Manual (2010). Stresstech Inc., Finland.

Yi, M.S., Hyun, C.M., Cho, S.H. \& Jang, T.W. (2009). A study of correction effect in T-bar according to cooling method, Proceeding of the 2009 Spring Annual Meeting of Korea Welding Society (in Korean).

Yi, M.S., Hyun, C.M. \& Paik, J.K. (2018a). Three-dimensional thermo-elastic-plastic finite element method modeling for predicting weld-induced residual stresses and distortions in Steel stiffenedplate structures, World Journal of Engineering and Technology, 6:176-200

Yi, M.S., Hyun, C.M. \& Paik, J.K. (2018b). Full-scale measurements of welding-induced initial imperfections in steel-stiffened plate structures, International Journal of Maritime Engineering, Vol.160, Part A4, October-December. 